\title{
Twenty years of load theory-Where are we now, and where should we go next?
}

\author{
Gillian Murphy $^{1}$ - John A. Groeger ${ }^{2}$ - Ciara M. Greene ${ }^{3}$
}

Published online: 4 January 2016

(C) Psychonomic Society, Inc. 2016

\begin{abstract}
Selective attention allows us to ignore what is taskirrelevant and focus on what is task-relevant. The cognitive and neural mechanisms that underlie this process are key topics of investigation in cognitive psychology. One of the more prominent theories of attention is perceptual load theory, which suggests that the efficiency of selective attention is dependent on both perceptual and cognitive load. It is now more than 20 years since the proposal of load theory, and it is a good time to evaluate the evidence in support of this influential model. The present article supplements and extends previous reviews (Lavie, Trends in Cognitive Sciences, 9, 75-82. doi:10.1016/j.tics.2004.12.004, 2005, Current Directions in Psychological Science, 19, 143-148. doi:10.1177/ 0963721410370295,2010 ) by examining more recent research in what appears to be a rapidly expanding area. The article comprises five parts, examining (1) evidence for the effects of perceptual load on attention, (2) cognitive load, (3) individual differences under load, (4) alternative theories and criticisms, and (5) the future of load theory. We argue that the key next step for load theory will be the application of the model to real-world tasks. The potential benefits of applied attention research are numerous, and there is tentative evidence that applied research would provide strong support for the theory itself, as well as real-world benefits related to
\end{abstract}

Gillian Murphy

gillian.murphy@ucc.ie

1 School of Applied Psychology, University College Cork, Cork, Ireland

2 Department of Psychology, University of Hull, Hull, UK

3 School of Psychology, University College Dublin, Dublin, Ireland activities in which attention is crucial, such as driving and education.

Keywords Selective attention · Perception · Perceptual load . Load theory $\cdot$ Distraction $\cdot$ Visual attention

Selective attention is the ability to focus on that which is important to the task at hand while ignoring or suppressing task-irrelevant information. A key question that has fuelled much debate and research in psychology is how, and crucially when, this irrelevant information is filtered out. For example, while reading this article the reader may be surrounded by many potential distractors, such as the noise of a fly buzzing around the room. Given the top-down goal of reading this article, how much information is available to you about the fly? Can the processing of irrelevant stimuli be reduced or even prevented by internal or external factors? The inability to ignore distractors is a common experience in daily life, and though it may at times have minor consequences, such as extending the length of time it takes to read an article, in other situations lapses of attention may have far more serious consequences (e.g., in healthcare situations, or while operating heavy machinery). Perceptual load theory (Lavie, 1995, 2005, 2010; Lavie \& Tsal, 1994) suggests that the success or failure of selective attention is dependent on the processing demands of the current task. That is, the level of perceptual load as well as any cognitive load will determine the efficiency of distractor rejection. This theory has been hugely influential over the last 20 years, with Lavie's, 1995 study "Perceptual Load as a Necessary Condition for Selective Attention" having been cited 1,385 times at the time of writing this article (source: Google Scholar). What made load theory attractive was that it proposed a solution to the long-standing "early versus late selection" debate, which had been the focus 
of attention researchers for decades (Driver, 2001). Despite this being an important step in attention research, outstanding issues and valid criticisms still surround load theory. This review will examine the state of the research to date-it is timely that we do so now, having passed the 20th anniversary of the load hypothesis (first proposed in Lavie \& Tsal, 1994).

The major reviews in this area are becoming outdated (Lavie, 2005, 2010). such is the speed with which new research is being published in the field, along with the shift in thinking that has occurred in the last number of years. Recently, the focus of load theory research has moved away from simply establishing the basic consequences of load and focused more on generalizing the theory beyond the original paradigms. Where load theory traditionally created a blackand-white distinction between perceptual and cognitive load and their opposing effects on attentional selection, recent research has contributed many more shades of gray. For example, research has focused on different forms of cognitive load, on different populations, and on the effects of different stimulus sets. Thus, both the limits and potential of load theory are at once becoming clearer, allowing more concrete applied predictions to be made. The more recent, independent reviews available are critical reviews, focusing on particular theoretical or methodological flaws in load theory, rather than on the broader state of the research and potential future directions (e.g., Benoni \& Tsal, 2013; Khetrapal, 2010). The purpose of the present review, then, is to supplement and expand upon previous reviews, with one eye on the applied future of the theory because that is, we feel, the crucial next step for load theory. This article has five major sections - evidence for the effects of (1) perceptual and (2) cognitive load to date, (3) individual differences research, (4) alternative theories, and finally, (5) the future of load theory. First, we present the theory itself and the circumstances that led to the model becoming so influential.

\section{Perceptual load theory}

A widely debated question in attention research has been whether selective attention operates at an early or late stage of processing. The "early-selection" view, first proposed in the 1950 s, holds that due to a limited perceptual-processing capacity (a "bottleneck" in the attentional process), individuals necessarily perceive only what they attend to; thus, focused attention can prevent distractor processing at an early stage (e.g., Broadbent, 1958; Treisman, 1969). Broadbent's filter theory is the classic example of "early selection," stating that incoming information is selected on the basis of physical features. This was typically demonstrated using dichotic listening experiments in which participants had to attend to one of two audio streams presented to the left and right ears. Participants were instructed to select one stream on the basis of features such as the gender of the speaker or the ear to which it was presented. The studies that supported the early-selection model typically used direct measures of awareness, such as recall for the unattended stream (e.g., Cherry, 1953). However, more indirect measures suggested that the bottleneck might not be absolute, with participants displaying increased galvanic skin response when words that had previously been paired with an electric shock were presented in the unattended stream (Moray, 1969). This evidence that selection could occur later, beyond the supposed "bottleneck," led some to favor a theory of late selection (e.g., Deutsch \& Deutsch, 1963; Duncan, 1980).

The "late-selection" view states that perception is of unlimited capacity and proceeds automatically, processing relevant and irrelevant stimuli indiscriminately. Late-selection theorists suggested that later processes such as memory or behavioral response are the ones affected by selective attention (Deutsch \& Deutsch, 1963; Duncan, 1980). They reconciled this theory with early-selection evidence by hypothesizing that the poor recall of unattended information in dichotic listening tasks was not due to early filtering of irrelevant information, but to late selection that prevented entry of that information to memory or deliberate behavior based on the information (e.g., Duncan, 1980). Although early selection initially gained the most empirical support (Cherry, 1953; Moray, 1959; Neisser, 1969; Sperling, 1960). in the late 70s the pendulum shifted, and the majority of evidence seemed to be in favor of late selection (e.g., Eriksen \& Eriksen, 1974; LaBerge, 1975; J. Miller, 1987; Posner, 1980).

Kahneman and Treisman (1984) argued that this new support for late selection was the result of a paradigmatic shift in attention research. The studies that supported early selection had often used the "filtering paradigm"- a strategy wherein participants are bombarded with information, both relevant and irrelevant, and asked to attend to a particular stimulus and provide a complex response (e.g., Cherry, 1953). The later studies that supported late selection were more likely to use the "selective set paradigm," in which participants are presented with a small number of stimuli and asked to perform a simple task (e.g., Posner, 1980). Kahneman and Treisman highlighted the differences between these paradigms and cautioned against any meaningful generalization across these studies. Yantis and Johnston (1990) then proposed a hybrid model of selective attention with a flexible locus of attention. Where early- and late-selection theorists had argued about where in the perceptual process the attentional filter was located, Yantis and Johnson suggested that the filter could move, depending on the task demands. When the task involved processing multiple objects, they found that attention could be perfectly selective. They argued for an early locus of attention when the task involved filtering out irrelevant objects, but that the locus could move to a late stage, postidentification, under certain conditions. 
Lavie and Tsal (1994) built on this idea by detailing what exactly determines the movement of the filter: perceptual load. Perceptual load theory states that perception is a limited-capacity process (similar to early-selection views) and proceeds automatically until that capacity is filled (in line with late-selection views). When a task imposes high perceptual load, capacity is reached and distractors cannot be processed, resulting in performance that is consistent with early selection. However, when a task involves low perceptual load, all available stimuli are processed, distractors and targets alike, necessitating late selection. Cognitive load, such as a high working memory requirement, can cause late selection to fail (Lavie, 2005).

To use the previous real-life example, how does one read this article while ignoring a fly buzzing around the room? How is it that this sentence is selected and the fly is rejected? Earlyselection theory dictates that as the fly is irrelevant, it would not be processed. This page would be selected for further attention at an early stage, and nothing about the fly would be processed beyond that point. Late-selection theory suggests that the fly (and other surrounding stimuli) would be processed along with the page. Selective attention would then take place at a later stage in processing, preventing the distractors from affecting behavior. Load theory incorporates aspects of both early and late selection to explain this scenario. If the visual properties of this article incurred high perceptual load (e.g., if the paper was transparent and the words written on the reverse of this page were visible here, demanding increased attention to distinguish these relevant words from the irrelevant distractor words), it is likely that the fly would be filtered out of the reader's awareness at the perceptual stage and not processed further; early selection occurs in this case because perceptual capacity is exhausted. If, however, the article incurred lower perceptual load (e.g., due to being written on thick, white paper with no translucent properties), the fly would be processed along with the page to a later stage of processing at which the reader must select the page and prevent the fly from interfering with the primary task. The allocation of attention at this late stage is dependent on the available cognitive resources, and it may fail if cognitive load is high. The process of selective attention is, according to load theory, dependent on both external properties (perceptual load) and internal properties (cognitive load).

Now we will break down the state of the research on load theory into five distinct branches - evidence for perceptual load effects, cognitive load, individual differences under load, criticisms and alternatives, and finally, the future of load theory.

\section{Perceptual load studies}

\section{Behavioral evidence}

Perceptual load is commonly manipulated in the visual domain in one of three ways. First, load can be altered by varying the number of items in the display. For example, in the frequently used flanker task (Eriksen \& Eriksen, 1974). participants are asked to identify which of the target letters $\mathrm{X}$ or $\mathrm{N}$ is present in a display. In a low-load trial, the target may appear alone, whereas in a high-load trial, the target may be surrounded by six neutral letters (e.g., Lavie \& de Fockert, 2003). The second manipulation of perceptual load in the visual domain is a manipulation of the similarity of the target and nontarget items, as is shown in Fig. 1 (e.g., Beck \& Lavie, 2005; Lavie \& Cox, 1997). For example, in the X-or-N search task, the extra letters can be visually dissimilar to the target in some way, such as their angularity. In a low-load trial, the extra letters may be all Os, whereas in a high-load trial, they may be angular letters that are more similar to the target (e.g., $\mathrm{K}, \mathrm{V}, \mathrm{W}$, and $\mathrm{Z}$ ). Finally, it is possible to keep the display constant between conditions and instead manipulate perceptual load by altering the task to be performed. This form of manipulation is often seen in experiments that require participants to make a judgment about an object-for example, viewing a briefly presented cross and reporting which arm, horizontal or vertical, is green (low load) or which arm is slightly longer (high load) (Cartwright-Finch \& Lavie, 2006); see Fig. 2A. Note that this paradigm has the benefit of using identical stimuli for both conditions.

The efficiency of selective attention in most visual studies is measured by the difference in target response times for trials containing congruent and incongruent distractors. If early selection takes place, then the distractor will not be processed, and so there will be no effect of congruency; however, if late selection occurs, then incongruent distractors will result in delayed responses and more errors. This congruency effect arises because the required response for the target is in direct conflict with the required response for the distractor.

Many behavioral studies have consistently shown that perceptual load affects the level of distractor interference (Forster \& Lavie, 2007a; Forster \& Lavie, 2008; Lavie \& Cox, 1997; Lavie \& Tsal, 1994; Rees, Frith, \& Lavie, 1997; Wei, Kang, \& Zhou, 2013). High perceptual load results in longer response times and higher error rates (due to the increased task difficulty), but it eliminates distractor interference (unlike general task difficulty). To investigate whether the observed effects of high perceptual load are simply a by-product of the increased task difficulty associated with high load and the simultaneous slowing of performance, Lavie and de Fockert (2003) conducted an experiment wherein the task display was subjected to extreme sensory degradation, so much so that the target could barely be seen. This was done to increase the task difficulty in a manner that could not be compensated for by simply applying more attention. If the effects of perceptual load were due simply to task difficulty, then they would also be evident with degraded stimuli. The researchers found that this was not the case: The altered stimuli reduced speed and accuracy relative to a clearly visible target, but crucially, they did not decrease distractor 


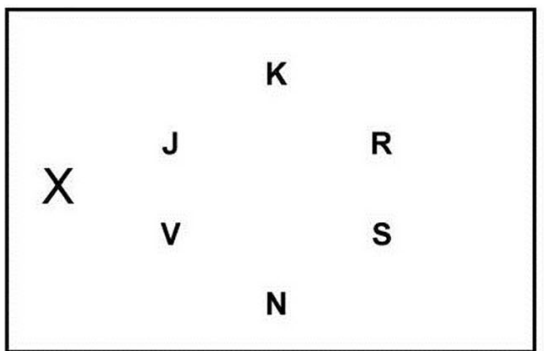

Fig. 1 Example of a classic load theory search task from Beck and Lavie (2005, p. 594). Participants must indicate whether an $X$ or $N$ is present in the circle of letters, while ignoring the peripheral distractor letter, which may be congruent or incongruent with the target (in this case, both are incongruent). In the low-load task (right), the target is surrounded by a number of identical round shapes, whereas in the high-load task (left), the target is surrounded by a number of different, angular shapes. Load theory predicts that because the distractor letter will be processed under low load,

interference. However, Yeshurun and Marciano (2013) recently manipulated stimulus degradation more systematically and found more complex patterns of results. Where Lavie and de Fockert (2003) only varied the degradation of the target (inadvertently making the distractor more salient), Yeshurun and Marciano varied (a) only the target, (b) only the distractor, and (c) both the target and the distractor. They found that distractor interference was evident at both low and high perceptual load, contrary to the predictions of load theory. The authors suggested that the relative conspicuity of the target is an important factor in determining the efficiency of selective attention, but they agreed that task difficulty does not explain load effects. The issue of conspicuity will be discussed in the section covering Criticisms of and Alternatives to Load Theory.

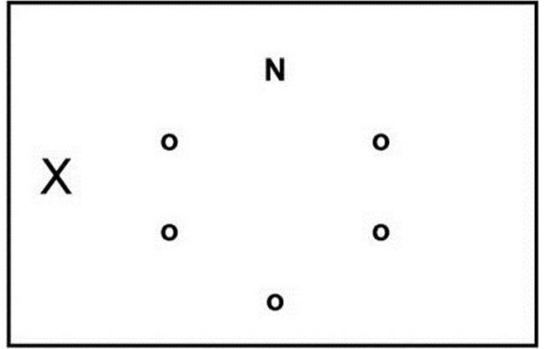

there will be a large distractor interference effect for response times (incongruent RT - congruent RT $=$ distractor interference effect). Under high load, because the distractor is not processed, the distractor interference effect will be significantly attenuated. From "Look Here but Ignore What You See: Effects of Distractors at Fixation,” by Beck and Lavie 2005, Journal of Experimental Psychology: Human Perception and Performance, 31, p. 594. Copyright 2005 by the American Psychological Association. Adapted with permission.

Proponents of the perceptual-load model claim that the reduction in distractor interference under high load is indicative of more focused attention (decreased distractor perception), though one could argue that it may be due to better rejection, or inhibition, of distractors. To resolve this uncertainty, Lavie and Fox (2000) investigated the effect of perceptual load on negative priming. Negative priming is the slowing of responses to previous distractor stimuli when the same stimuli are presented as targets on later trials (Tipper, 1985). Negative priming has been viewed as evidence for late selection (Driver, 2001). as it reflects active distractor inhibition, whereby distractors are perceived but then inhibited at a later stage. Lavie and Fox found negative-priming effects from distractors presented under low perceptual load; however,
A

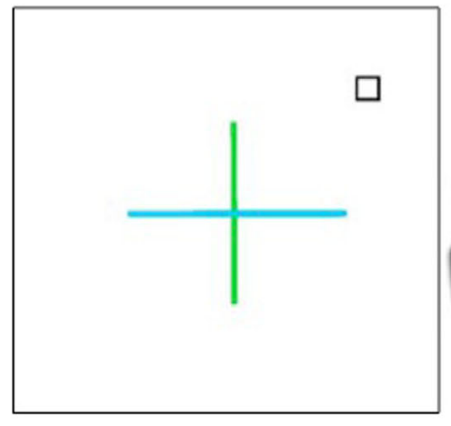

B

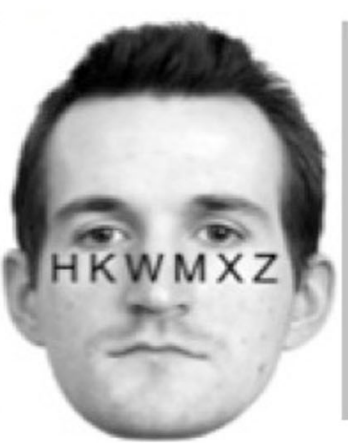

C

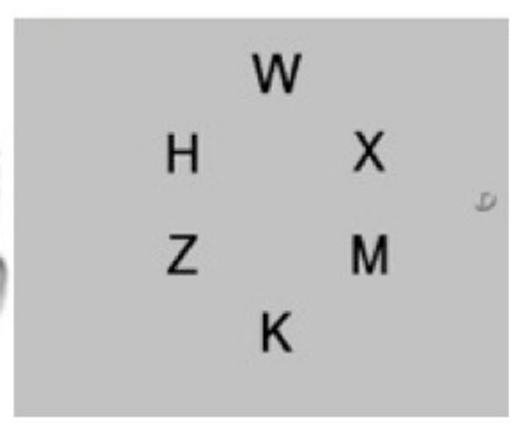

Fig. 2 Example stimuli from paradigms investigating perceptual load effects on awareness. (A) The final, critical trial from Cartwright-Finch \& Lavie (2006), as illustrated in Lavie (2006). The stimulus was identical for both low- and high-load trials, but under low load the task was simpler ("identify which arm is blue") than under high load ("identify which arm is longer"). On the final trial, an unexpected shape was presented along with the cross, and awareness of the shape was assessed. Awareness was significantly worse under high load. (B) High-load trial from Jenkins, Lavie, and Driver (2005). Participants were presented with a letter search task that was superimposed onto a human face that participants were instructed to ignore. Following the task, they were given a surprise recognition memory test for the irrelevant faces, and recognition was found to be significantly worse under high load. From "Recognition Memory for Distractor Faces Depends on Attentional Load at Exposure," by Jenkins, Lavie, \& Driver, 2005, Psychonomic Bulletin \& Review, 12, p. 315. Copyright 2005 by the Psychonomic Society. Reprinted with permission. (C) Example of a high-load trial from Macdonald and Lavie (2008). During a perceptual-load letter-search task, participants' awareness for a small, unexpected shape was assessed. Detection sensitivity was significantly worse under high load. From "Load Induced Blindness," by Macdonald \& Lavie, 2008, Journal of Experimental Psychology: Human Perception and Performance, 34, p. 1080. Copyright 2008 by the American Psychological Association. Reprinted with permission. 
these effects were eliminated when the perceptual load was increased. Greater negative priming under low load suggests greater distractor inhibition under low load. This is the opposite of what would be predicted if the effects of high perceptual load were due to better inhibition. The authors therefore concluded that the reduced distractor interference under high load that has been demonstrated in the literature is unlikely to be caused by increased distractor inhibition, but instead is most likely a result of decreased distractor perception. This supports the key prediction of the perceptual-load modelincreased perceptual demand prevents the processing of unattended information, resulting in reduced distractor interference, rather than improved distractor inhibition.

\section{Distractors}

The perceptual-load model focuses on the ability to ignore irrelevant distractors, making the definition of an irrelevant distractor crucial. Forster and Lavie (2008) conducted an experiment using a letter search task comparing interference from response-competing distractors (letters) with interference from distractors deemed truly irrelevant (cartoon characters). The researchers chose cartoon characters as distractors because previous research had suggested that they are a particularly distracting type of stimuli, as they possess characteristics such as visual salience and meaningfulness. The results showed that irrelevant distractors were just as likely to interfere with task performance as relevant distractors, and importantly, their interference effects could also be reduced to the same degree via high perceptual load. This study has important implications for the practical application of load theory, as it suggests that the response-competing qualities of a distractor do not interfere with the predictions of load theory.

However, there is evidence that special distractors continue to cause interference under high perceptual load. Faces have an obvious biological and social significance, and it has long been suggested that they might be a special case in attention (see Farah, Wilson, Drain, \& Tanaka, 1998, for a review). Neuroimaging research suggests that faces may be processed by a specialized module (De Renzi, 2000; Kanwisher, McDermott, \& Chun, 1997). Lavie, Ro, and Russell (2003) investigated this possibility in relation to perceptual load. They found that whereas distraction from meaningful, nonface objects (e.g., fruits, musical instruments) was eliminated under high perceptual load, distraction by celebrity faces remained. This effect was replicated by S. Sato and Kawahara (2014). who found that the attentional capture by distractor faces persisted even when they had a different onset time than the search array. This result was not apparent when this experiment was replicated using animal faces as distractors (Hains \& Baillargeon, 2011). which might suggest that this finding is reflective of the special significance of human faces and/or of our expertise with them. Evidence from event-related potentials (ERPs) also suggests that human faces are a special case. In an ERP study, Neumann, Mohamed, and Schweinberger (2011) compared repetition effects in the processing of unfamiliar distractor faces, houses, and hands. Participants were presented with a perceptual-load letter search task (as in Fig. 1), superimposed on a background image of an unfamiliar (i.e., noncelebrity) face, house, or hand. Later, images of faces, houses, and hands were presented without the letter task. Some of these were repeats from the earlier trials, and some were new stimuli. Brain activity is thought to be modulated in response to stimuli that are repeated (e.g., GrillSpector, Henson, \& Martin, 2006; Henson, Shallice, \& Dolan, 2000), and thus this paradigm allows for an estimation of background distractor processing in the letter search task. Neumann and colleagues found evidence of repetition modulation for faces, whereas no such effect occurred for houses or hands. Importantly, the repetition modulation for faces was not extinguished under high perceptual load, suggesting that faces are a special case in the load theory model, continuing to be processed even when a central task imposes high perceptual load. Recently, it has been suggested that attention capacities may even be divided between "face capacity" and "nonface capacity" (Thoma \& Lavie, 2013). Thoma and Lavie's behavioral study showed that face and nonface loads had different effects on face distractor interference: Face load eliminated face distraction easily; however, nonface load had no effect on face distraction. This study suggests that faces are special because they are processed separately, but by exhausting the capacity of the facial-processing module, the predictions of load theory can be upheld.

However, an opposing body of evidence suggests that the observed ability to process distractor faces under high load may not be due to a face-selective attention module, but instead may be a result of expertise. There is evidence that visual expertise for other objects can induce the same effect. Neuroimaging studies of experts in birds and cars have shown that the same area of the brain that is used for face processing is recruited in the processing of the object of the participant's expertise (Gauthier, Skudlarski, Gore, \& Anderson, 2000). This expertise hypothesis was tested by Ro, Friggel, and Lavie (2009) in a follow-up to the study on famous faces. They found that expert musicians suffered distractor interference from musical instruments under high perceptual load. For nonmusicians, there was a significant effect of set size, with the distractor interference effect decreasing as set sized increased. However, musicians showed no effect of set size. Thus, it could be argued that the previously discussed evidence in favor of the "special case" of faces may simply be reflective of a specialized processing mechanism for objects of high familiarity, one that is either more efficient or has a greater capacity. He and Chen (2010) also found that interference from familiar natural distractors persisted under high perceptual load, whereas Lin and Yeh (2014) found that when one's 
own name or another person's name was presented as a distractor in a search task, participants were more likely to recall seeing their own name than the other name, even under high load.

The proposed existence of a specialized face-processing module is an ongoing debate that has yet to result in a consensus, but from a load theory perspective, what is important to note is that not all distractors are equal. Whether the difference is due to the special case of faces or expertise, what you are trying to ignore is almost as important as what you are trying to attend to. This is quite an important point to note when applying the load model to real-life tasks.

\section{Awareness under load}

The behavioral evidence discussed thus far has focused on the degree to which distractors can be ignored - a rather indirect measure of processing. There is also evidence that load influences conscious, in-the-moment awareness of distractors, in the form of inattentional blindness research (see Lavie, Beck, \& Konstantinou, 2014, for a review). "Inattentional blindness" is the failure to notice a visible stimulus because one's attention was consumed with another task. Cartwright-Finch and Lavie (2006) instructed participants to make a discrimination about a cross that incurred low load (which arm is green?) or high load (which arm is longer?); see Fig. 2A. Participants' awareness of a small black square that appeared on the critical final trial was assessed immediately via direct questioning. Reported awareness of the shape was 40\%-50\% lower in high-perceptual-load conditions. Recent research suggests that this inattentional blindness caused by high load occurs at an early stage of processing (Calvillo \& Jackson, 2014). While participants performed a low- or high-load categorization task, Calvillo and Jackon presented them with an unexpected additional object that was either animate or inanimate. Awareness for the unexpected object was assessed immediately after the critical trial. Previous studies had established that animate objects are detected more quickly and easily than inanimate objects, with animate and inanimate objects activating different visual brain regions (ventrolateral and ventromedial regions; Wiggett, Pritchard, \& Downing, 2009). Calvillo and Jackson found that under low load, animate objects were significantly more likely to be detected than inanimate objects; however, this effect was eliminated under high load. This suggests that even basic categorization of distractor stimuli is prevented under high perceptual load, which in turn affects the predicted levels of awareness.

As with traditional inattentional blindness research, one interpretation of these results is inattentional amnesia (Wolfe, 1999) - that participants did process the unexpected object but forgot they had seen it. Indeed, there is evidence that perceptual load affects memory for distractors. Jenkins, Lavie, and Driver (2005) presented participants with a letter search task superimposed on a human face (see Fig. 2B). Their participants were told to ignore the distractor face throughout the experiment, but were then presented with a surprise test. Memory for the distractor face was dependent on the perceptual load at exposure, with faces displayed in low-load tasks being recognized more often than those presented in high-load tasks. This suggests that load in a nonface task can reduce memory for a face - that, in line with the predictions of load theory, perceptual capacity is limited, and beyond a certain threshold, information can no longer be processed. Failing to recognize task-irrelevant information does not necessarily mean that participants were unaware of the faces; it is possible that the stimuli were simply not processed sufficiently to allow later recognition. Addressing this, Macdonald and Lavie (2008) conducted a follow-up study, which measured in-themoment awareness of a target shape, rather than relying on questioning at the end of the experiment. While undertaking a traditional perceptual-load search task in which a target letter (X or $\mathrm{N}$ ) was sought among nontarget letters, participants were asked to report the presence of a small gray shape that could appear on some trials (see Fig. 2C). The results showed that the shape was detected $90 \%$ of the time under low perceptual load, but only $37 \%$ of the time under high perceptual load. This suggests that the level of load in a task truly modulates conscious awareness of additional information, rather than just affecting postevent recall.

This strand of research is important for the real-world applications of load theory, because failing to detect objects can be just as troublesome as being distracted, since many activities and occupations are dependent on noticing unexpected objects. Although the traditional load theory paradigms rely on distractor interference as a measure of the efficiency of selective attention, it is of course important to note that in the real world, being immune to the "distraction" of nontargets may not be beneficial. For example, when driving, a pedestrian on the footpath may be a distractor, but should that pedestrian turn to cross the road, they become a potential hazard that ought to be attended to. A complete understanding of loadinduced blindness could be applied to numerous domains, as will be discussed later in this article.

\section{Neuroimaging evidence}

Though the load theory model does not describe the mechanisms at work, a body of neural evidence supports the effect of perceptual load. Torralbo and Beck (2008) have theorized that perceptual load affects distractor interference via a top-down biasing signal that arises as a consequence of neural competition. Previous functional magnetic resonance imaging (fMRI) studies have established that when stimuli are presented simultaneously in the visual field, their cortical representations in the object recognition pathway interact in a mutually suppressing manner (Beck \& Kastner, 2005; Kastner, De Weerd, 
Desimone, \& Ungerleider, 1998). Single-cell recordings in extrastriate cortex in monkeys have found that the response to a target presented within a neuron's receptive field is reduced when a second stimulus is presented simultaneously within the same field (Connor, Preddie, Gallant, \& Van Essen, 1997; Miller, Gochin, \& Gross, 1993; Moran \& Desimone, 1985). Stimuli are thus not processed independently, but rather interact competitively, at least when they are "close" to each other in a particular modality (temporally, spatially, etc.). Macaque studies, however, have shown that when attention is directed to the target stimuli, the neural response is as large as when the stimulus is presented alone (Reynolds, Chelazzi, \& Desimone, 1999). This suggests that directing attention to a target overcomes the suppressive influence of distractor stimuli in a top-down manner. These studies support the biasedcompetition model of selective attention (Desimone \& Duncan, 1995). in which neural competition for representation is said to be controlled by both bottom-up factors (e.g., when one stimulus is more novel) and top-down factors (e.g., when one stimulus is more situationally relevant).

Torralbo and Beck (2008) argued that this top-down bias is at the heart of the neural mechanisms underlying perceptual load. The degree of competition between stimuli dictates the strength of the required top-down biasing mechanism, which in turn determines the degree to which the unattended stimulus is processed. Displays that induce a high degree of competition will require a strong bias to overcome the competition and select the target for further processing. This amounts to high perceptual load and ensures that the competing stimulus is ignored. Conversely, if there is minimal competition between task-relevant stimuli, very little top-down bias is necessary to overcome the conflict, amounting to low perceptual load. This theory is in line with much of the current body of evidence for load theory (Scalf, Torralbo, Tapia, \& Beck, 2013).

In a behavioral study, Torralbo and Beck (2008) found that stimuli that should produce greater competition in the visual cortex resulted in reduced distractor interference effects, akin to high perceptual load. In a search task, a display of four closely spaced letters resulted in less distractor interference than a similar display with the same letters spaced farther apart. Distractor interference was also reduced when the targets and nontargets appeared in the same hemifield rather than in different hemifields, as local interactions occur within rather than between hemifields (Torralbo \& Beck, 2008). This finding was replicated in a recent behavioral study (Wei et al., 2013). Similarly, Parks, Beck, and Kramer (2013) found that steady-state visual evoked potentials for distractors were reduced under high perceptual load when the distractor was positioned close to the target location, but this effect was not evident at more eccentric locations. These results suggest that increased perceptual load induces a relatively narrow area of improved distractor resistance. Distractor filtering does not appear to occur across the visual field, but rather as a direct result of the resolution of competitive interactions in the visual cortex. This contradicts classic load theory, in that it suggests that there is no single visual "perceptual capacity" that can be exhausted by load. Clearly, more research will be needed to define the mechanisms that underlie visual perceptual load at a neural level.

Although there is still debate as to the exact mechanisms at work, studies have shown that the level of perceptual load in a given task modulates neural activity related to distractors. This has been illustrated using fMRI (Fu, Fedota, Greenwood, \& Parasuraman, 2010; O'Connor, Fukui, Pinsk, \& Kastner, 2002; Sy \& Giesbrecht, 2010; Wei et al., 2013; Xu, Monterosso, Kober, Baldois, \& Potenza, 2011; Yi, Woodman, Widders, Marois, \& Chun, 2004), electroencephalography (EEG; Fu, Huang, Fedota, Greenwood, \& Parasuraman, 2009; Handy, Soltani, \& Mangun, 2001; Parks et al., 2013; Parks, Hilimire, \& Corballis, 2009, 2011; Rauss, Pourtois, Vuilleumier, \& Schwartz, 2009; Rees et al., 1997; Rorden, Guerrini, Swainson, Lazzeri, \& Baylis, 2008; Schwartz et al., 2005; Wang et al., 2012). and both simultaneously (Sabri et al., 2013). Other neuroimaging evidence has identified a push-pull relationship between targets and distractors in V4 (Pinsk, Doniger, \& Kastner, 2004; i.e., enhanced attention to a target occurs at the expense of other stimuli in the display). This is in line with the principle of competitive interactions, which suggests "if one stimulus is 'pushed up' by attention then, by virtue of their competitive/inhibitory connections, other competing stimuli will necessarily be 'pulled down"' (Scalf et al., 2013, p. 6). Crucially for load theory, there is evidence that the extent of this push-pull dynamic is moderated by the level of perceptual load of the central task. For example, ERP studies suggest that increased perceptual load in the relevant task results in stronger N1 responses to relevant information and weaker N1 signals to irrelevant information (Rorden et al., 2008). The visual N1 is a component that reflects processing of any visual stimulus, but the amplitude is larger for attended-location than for unattendedlocation stimuli (Luck et al., 1994). Research suggests that the $\mathrm{N} 1$ component is reflective of the discrimination process in selective attention (Vogel \& Luck, 2000). Fu et al. (2010) also found that under high load, the N1 amplitude was greater in the attended than in the unattended hemifield, whereas no significant difference occurred under low load.

Moving distractors are often used to assess the related activity in the visual cortex. In a study investigating early evoked potentials, participants were asked to indicate whether a word was presented in upper case or lower case (low load) or to count the number of syllables in the word (high load) while ignoring an irrelevant motion background (Rees et al., 1997). Under low load, the distractor background evoked responses in areas of the brain responsive to movement (e.g., MT, V1/ V2, V5), but such responses were markedly reduced under high load. 
In a similar fMRI study, Yi, Woodman, Widders, Marois, and Chun (2004) instructed participants to ignore pictures of houses (of both the inside and the outside) presented in the background while monitoring for face repetitions at the fixation point. The perceptual load of the faces being monitored was varied by adding noise (random salt-and-pepper distortions) to each face. Yi and colleagues found that parahippocampal activity related to the background scenes was substantially reduced under conditions of high load. They also found evidence of repetition suppression under low load; that is, upon repetition of a background scene, the stimulus signal weakened considerably. Such an effect was eliminated under high perceptual load, suggesting that the brain was less sensitive to repetition under high load.

Schwartz et al. (2005) and O'Connor, Fukui, Pinsk, and Kastner (2002) used peripheral checkerboards as distractors while participants performed a centrally presented task. Both studies showed that activity across the visual cortex related to the checkerboards (from V1 to V4) was significantly reduced with a high-load central task as compared to with a low-load task. Using retinotopic mapping, O'Connor and colleagues found that activity in the lateral geniculate nucleus (LGN) related to the irrelevant checkerboards was also modulated by load. The LGN is the relay center for messages sent by the retina and is said to be the first point of access for sensory information into the visual cortex (Jones, 1985; Sherman \& Guillery, 2001). As this is the first point at which top-down signals could affect visual processing, perceptual load can thus be said to affect the earliest processing site in the visual pathway. Because this was an fMRI study in which the blood oxygen level dependent signal was integrated over seconds, it is possible that the altered activity in the LGN was a product of feedback from other areas (Briggs \& Usrey, 2011; Ichida, Mavity-Hudson, \& Casagrande, 2014). However, this study suggests that, in line with the predictions of load theory, there is a qualitative difference in processing between conditions of low and high perceptual load.

Though most of the evidence discussed here was related to visuo-spatial attention, the effect of perceptual load has also been observed with auditory stimuli (e.g., Sabri et al., 2013). Both $\mathrm{PMRI}$ and EEG were used to analyze neural responses during a dichotic-listening experiment. Participants performed a signal detection task with one ear (discriminating between short- and long-duration tones) and ignored the sounds in the other ear. The short tone was always $50 \mathrm{~ms}$. In the low-load condition, the long tone was $100 \mathrm{~ms}$, whereas in the high-load condition, the long tone was $60 \mathrm{~ms}$, forcing a more difficult discrimination. Participants' ability to detect an irrelevant deviant tone among the standard irrelevant tones was assessed. EEG results showed that the mismatch negativity response $(\mathrm{MMN})$, which is associated with the passive detection of deviant stimuli, was larger in the low-load task.

\section{Cross-modal perceptual-load studies}

Visual and auditory studies of perceptual load have been discussed thus far; however, the real world is rarely unimodal, and attention often functions across multiple senses simultaneously. What is the effect of perceptual load in one modality on distractor inhibition in another? This question must be addressed before load theory can move forward with applied research. The literature remains divided on this issue, though it has been a focus of much research in recent years. There is considerable theoretical and empirical support for the view that attentional resources are modality-specific (Allport, Antonis, \& Reynolds, 1972; Parks et al., 2011; Treisman \& Davies, 1973; Wickens, 1980). with load in one mode having no effect on distractor inhibition in another. For example, in a PET study, Rees, Frith, and Lavie (2001) found no difference in the distraction caused by an irrelevant motion distractor under high and low audio load. Participants were asked to identify loudly spoken words among quietly spoken words (low load) or to identify bisyllabic words among monosyllabic and trisyllabic words (high load), while ignoring irrelevant visual motion stimuli. Rees and colleagues (2001) found that motion-related visual areas were activated by the irrelevant stimuli in both the low- and high-perceptual-load conditions, suggesting that perceptual-load effects are evident within but not between modalities.

However, there is also evidence that capacity limits are supramodal, with load in one mode increasing distractor inhibition across all senses (Berman \& Colby, 2002; Broadbent, 1958; Houghton, Macken, \& Jones, 2003; Klemen, Büchel, \& Rose, 2009; Parks et al., 2009). For example, one fMRI study revealed that angry distractor voices produced altered responses in the amygdala and auditory cortex, relative to neutral voices, under low visual load, whereas this difference was eliminated under high visual load (Mothes-Lasch, Miltner, \& Straube, 2012). Further evidence for supramodal capacities has emerged from studies investigating awareness of distractors. Macdonald and Lavie (2011) established the phenomenon of "inattentional deafness" in visual perceptual-load studies. In a paradigm similar to the inattentional blindness experiments described above, participants were asked to perform discrimination about a cross and to report when they heard a brief tone played in the room. Under high perceptual load, participants were significantly less likely to report hearing the sound, suggesting that the amount of visual load affected the degree to which audio distractors were processed.

Methodological differences across these studies make it difficult to draw conclusions, but a recent study by Jacoby, Hall, and Mattingley (2012) can perhaps offer a resolution to this conflicting evidence. Neural responses (steady-state evoked potentials) to an irrelevant checkerboard were measured under levels of visual and audio perceptual load. In line with load theory, high perceptual visual load led to decreased 
responses to the irrelevant visual distractor. However, when the target was auditory, high audio load actually increased responses to the distractor checkerboard. A previous behavioral study showed similar results when the distractor was auditory-increasing visual perceptual load eliminated distraction by irrelevant visual distractors but increased distraction by audio distractors (Tellinghuisen \& Nowak, 2003). Tellinghuisen and Nowak suggested that the same resources that direct attention to task-relevant stimuli are also critical in inhibiting distraction arising from nonattended modalities. Therefore, an increase in perceptual load in the attended modality will have two distinct effects: It will improve distractor rejection within the attended modality by exhausting the available capacity, while simultaneously weakening the suppression of stimuli from other senses (Jacoby et al., 2012). In the language of load theory, cross-modal tasks require more executive control, amounting to cognitive load (BrandD'Abrescia \& Lavie, 2008). As is predicted by the load model, this cognitive load disrupts late selection processes, leading to greater distraction. Some resources, such as perceptual capacity, may be modality-specific, accounting for previous findings in which load in one modality had no effect on processing in another (Rees et al., 2001). However, when the task requires the recruitment of executive control processes, increases in distraction become apparent, because top-down control is modality-independent.

\section{Cognitive load}

The literature reviewed so far indicates clearly that distractors are more difficult to ignore under conditions of low perceptual load. However, individuals do not completely fail to reject distractors under low perceptual load; instead, we would expect to see both within- and between-subjects variations in ability to focus on the primary task. Under low perceptual load, then, what determines the effectiveness of selective attention? How do individuals achieve late selection, preventing perceived distractors from affecting behavior? Lavie's (2010) model theorizes that executive functions are responsible for late selection, as they are known to be involved in top-down, goal-directed behavior, actively maintaining current priorities. This is evidenced by neuropsychological studies in which those with damage to the frontal lobe can suffer from "dysexecutive syndrome." This disorder is characterized by an inability to suppress response to irrelevant distractors and difficulty maintaining behavior in line with current goals (Baddeley \& Wilson, 1988). Interestingly, the frontal lobe is also known to be the last to develop in young people and the first to deteriorate in old age. This may explain the increased distractor interference that has been shown in children (Couperus, 2011) and the elderly (Maylor \& Lavie, 1998). Indeed, research has shown that individual differences in distractibility are highly associated with individual differences in cognitive control capacities (Engle, 2002).

Research has shown that loading executive functions ("cognitive load") has an effect opposite the effect of perceptual load. When cognitive load is high, it is more likely that distractor inhibition will fail and distractor interference effects will be observed. Using the earlier example of reading an article while ignoring the buzzing of a fly in the room, imagine that the reader is also trying to actively remember a phone number while reading (placing a high load on working memory). This would make the reader much more vulnerable to the distracting effects of the fly, as there would not be sufficient remaining cognitive resources to maintain top-down, goaldirected behavior. The literature has traditionally loaded cognitive function through working memory tasks, and numerous studies have shown that high working memory load disrupts selective attention (Burnham, 2010; Lavie \& de Fockert, 2005; Lavie, Hirst, de Fockert, \& Viding, 2004). Participants complete a "sandwich task" (see Fig. 3); that is, they are first presented with something to remember; then, while maintaining it in memory, they must complete a response-competition visual search task, before answering a question about the tobe-remembered item (e.g., de Fockert, Rees, Frith, \& Lavie, 2001). In this manner, the effect of working memory load on distractor interference can be examined. Although most studies in this area have manipulated visual and auditory attention, a novel study investigated the effect of cognitive load on tactile selective attention. Dalton, Lavie, and Spence (2009) instructed participants to focus on target vibrations while ignoring distractor vibrations. They found that high working memory load resulted in greater distractor interference. There is also evidence that neural responses to irrelevant distractors increase under high cognitive load (de Fockert et al., 2001; Kelley \& Lavie, 2010; Rissman, Gazzaley, \& D’Esposito, 2009).

The predictions of load theory with regard to cognitive load are rather simplistic - "cognitive load increases distractor interference." There are many different forms of cognitive load; however, load theory research has almost exclusively used a simple working memory task (remembering a list of numbers). Recent research has taken a closer look at the term "cognitive load" and shown that not all working memory tasks are equal, with different types of tasks having different effects.

Baddeley's working memory model has several components: the "slave systems" that process and maintain information (the phonological loop and visuo-spatial sketchpad), a system responsible for binding information together (the episodic buffer), and the supervisory system that governs the activity of the rest (the central executive) (Baddeley, 2000; Baddeley \& Hitch, 1974). Although most studies of cognitive load have used verbal working memory tasks (e.g., remembering a series of numbers or letters), a recent study attempted to assess the effect of loading other working memory 


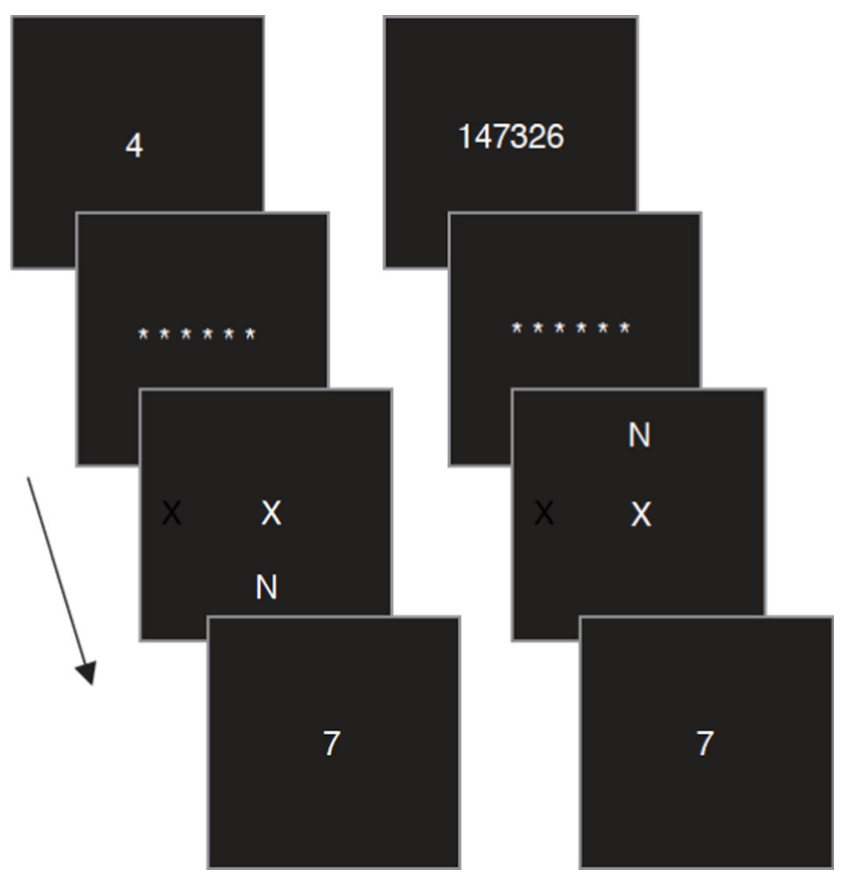

Fig. 3 Typical procedure for assessing the effects of low (left) and high (right) working memory load on attention (Lavie, 2005, p. 76). Participants are first presented with a number of digits to remember and instructed to hold them in memory throughout the trial. They are then presented with a search task (in this case, a response competition task) that they must complete as quickly and accurately as they can. Participants are then presented with a probe digit and must indicate whether the probe had appeared in the initial memory set. The response times and accuracy for the search tasks are assessed, excluding any trials on which the response to the memory probe was incorrect. In general, working memory load's effect is opposite the effect of perceptual load: It increases distraction by irrelevant stimuli. From "Distracted and Confused? Selective Attention Under Load," by N. Lavie, 2005, Trends in Cognitive Sciences, 9, p. 76. Copyright 2004 by Elsevier Ltd. Adapted with permission.

components (Burnham, Sabia, \& Langan, 2014). For participants performing a visual search task (identifying a green diamond among five or nine green circles), loading the central executive (i.e., participants were given a starting number and had to complete a backwardcounting task for the duration of the trial), visual working memory (remembering four colored squares and indicating whether a probe color was present in the original set), and spatial working memory (remembering the locations of two squares and indicating whether two probe squares were in the same locations as the original set) increased distraction. However, loading phonological working memory (remembering two monosyllabic three-letter words and indicating whether a probe word was in the original set) had no effect on attentional capture in the search task. This suggests that not just any working memory load influences distractor rejection, but rather, only working memory tasks that require the same resources as the search task. In line with load theory's general principles, it is a question of limited resources and processing limitations. This has interesting implications for real-life attention, in which resources are commonly tapped by two tasks simultaneously (e.g., holding a picture of a map in memory while walking).

However, there is some conflicting evidence in this area. Rose, Schmid, Winzen, Sommer, and Büchel (2005) found that, contrary to the predictions of load theory, increasing the load in a working memory task ( $n$-back) decreased the processing of task-irrelevant visual stimuli (background images). They assessed irrelevant-object processing in a series of behavioral, fMRI, and EEG studies, finding that increasing working memory load reduced the processing of irrelevant objects, in the same manner as increasing perceptual load. These apparently contradictory findings may simply be a result of imprecise definitions of "cognitive load." Within Baddeley's working memory model, there is a clear distinction between tasks that require maintenance and tasks that require cognitive control, with neuroimaging research indicating that these tasks require the differential recruitment of prefrontal cortex regions (Baddeley, 1992; Smith, Jonides, Koeppe, \& Marshuetz, 1998). Konstantinou and Lavie (2013) hypothesized that this distinction would manifest in perceptual-load studies, with visual working memory load (maintenance) reducing visual representation capacity, and recall of randomly ordered digits in proper order (cognitive control) reducing top-down control of priorities. The effect of maintenance was assessed with a simple spatial memory task in which participants memorized a set of colored squares, and cognitive control was manipulated via the "successor naming task" in which participants remembered a number of digits in order. Participants were then prompted with a single probe digit and had to indicate which digit came after the probe. During the retention interval of the working memory task, participants performed a visual search task while also monitoring the periphery for a masked shape. In line with Konstantinou and Lavie's predictions, they found that visual working memory load reduced the ability to detect a peripheral shape in a visual search task, presumably due to reduced visual-processing capacity (similar to the effects of high perceptual load; see Fig. 4). Loading cognitive control, however, had the opposite effect, with increased sensitivity to the peripheral shape. This reflects a lack of priority-based control of attention, in accordance with classic load theory predictions relating to cognitive-load effects.

These results conflict with a previous study that compared a maintenance-based working memory task (remembering a string of digits) and a working memory task that involved executive control (rearranging the order of the numbers; Fougnie \& Marois, 2007). The executive control task was significantly more likely to induce inattentional blindness for an unexpected shape, though Konstantinou and Lavie (2013) argued that this result was likely due to a confounding increase in general task difficulty. Konstantinou and Lavie suggested 


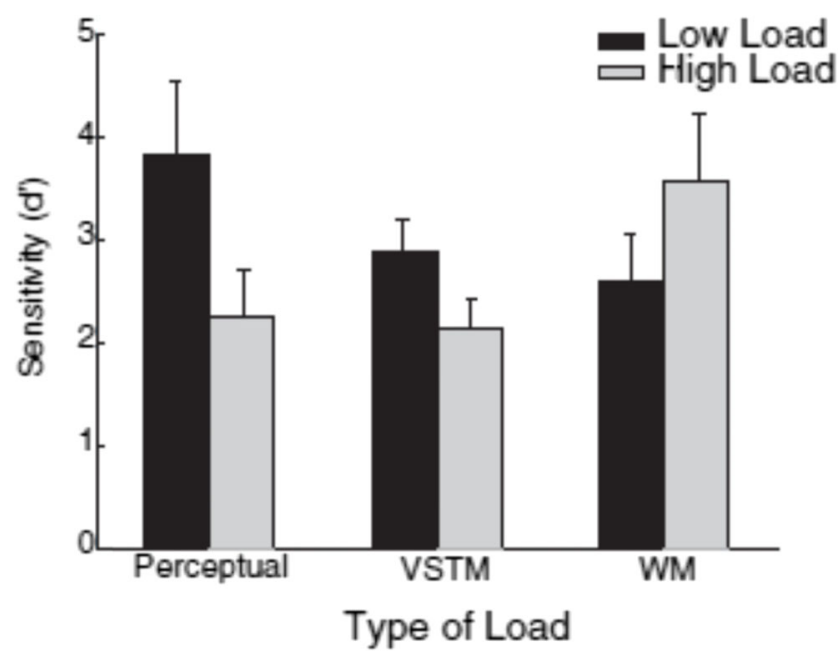

Fig. 4 Results from Konstantinou and Lavie (2013). Effects of perceptual load, visual short-term memory load (requiring simple maintenance), and working memory load (requiring cognitive control) on awareness of a shape presented adjacent to a central search task. Loading cognitive control (WM) has an effect opposite that of a maintenance memory task (VSTM): It increases awareness of the shape. From "Dissociable Roles of Different Types of Working Memory Load in Visual Detection," by Konstantinou \& Lavie, 2013, Journal of Experimental Psychology: Human Perception and Performance, 39, p. 922. Copyright 2013 by the American Psychological Association. Reprinted with permission.

that accurately distinguishing between different types of working memory explains the discrepancy in previous findings, with methodological differences between studies in which cognitive load increased distractor interference (Carmel, Fairnie, \& Lavie, 2012; Lavie \& de Fockert, 2005; Lavie et al., 2004) and those in which cognitive load reduced distractor interference (Bollinger, Masangkay, Zanto, \& Gazzaley, 2009; Rose et al., 2005; Sreenivasan \& Jha, 2007). This distinction has since been replicated (Konstantinou, Beal, King, \& Lavie, 2014; Roper \& Vecera, 2014). strengthening the cognitive-load-related claims of load theory.

The distinction between the effects of different kinds of memory load will be important for future studies that manipulate load to note. This research also sparks an interesting question as to the possible effects of other types of cognitive load and their potential interactions with perceptual load (e.g., the processes of judgment, decision making, and prospective memory are ripe for examination). A review of the load theory literature suggests that far more research has been conducted on the topic of perceptual load than on cognitive load over the past 20 years. However both types of load play important roles in determining selective attention performance. Further research into other forms of cognitive load (and their interactions with perceptual load) would be beneficial for both theoretical and applied purposes, as the concept of cognitive load in load theory has been somewhat neglected.

\section{Individual differences under load}

Load theory, depending as it does on capacity limitations, predicts individual differences in response to distractors. Processing capacity is known to develop during childhood and to deteriorate later in life. Research conducted with children and the elderly has shown that the effects of visual selective attention are the same in both groups as for younger adults; however, they show differences in what constitutes low and high load. Maylor and Lavie (1998) found that among older adults, a smaller increase in perceptual load would decrease distractor interference. Similar studies involving children have shown that young children require less perceptual load than either older children or adults to induce early selection (Couperus, 2011; Huang-Pollock, Carr, \& Nigg, 2002). All three studies revealed that performance in both groups matched that of young adults in high-load but not low-load tasks. This suggests that early selection may engage processes that mature earlier and regress later than late selection processes. Younger children have also been found to be more susceptible to inattentional blindness under low and moderate levels of load than are slightly older children (Remington, Cartwright-Finch, \& Lavie, 2014).

Similarly, cognitively impaired individuals have less perceptual capacity, and so require a smaller increase in load in order to induce early selection. Research has shown that individuals with a brain lesion in areas associated with attention respond to perceptual load similarly to children and older adults (Lavie \& Robertson, 2001). Patients with a right parietal lesion demonstrating left neglect are extremely vulnerable to distracting stimuli in their right visual field, but Lavie and Robertson found that a small increase in the perceptual load of the central task resulted in reduced interference by right distractors. This effect was observed by increasing the set size of a letter search task from one to two, a change that had no effect on healthy controls. This suggests that the lesions have a direct effect on attentional capacity, reducing the amount of perceptual load necessary to induce early selection. Similar results have been observed in people with schizophrenia and schizotypal personality (Ducato, Thomas, Monestes, Despretz, \& Boucart, 2008). There has been disagreement as to whether schizophrenia results in reduced or increased attentional capacity, with many studies producing different results using different paradigms. Ducato et al. suggested that perceptual load could be responsible for these discrepancies, and indeed they found that under low load, all participants showed distractor interference. As load increased from low to medium, only participants with schizophrenia or schizotypal personality disorder demonstrated reduced distractor interference. Medium load had no effect on the controls. This suggests that schizophrenia may be associated with a reduced perceptual capacity, not an improved ability to filter out distractors. This is just one example of how load 
theory, with its simple predictions founded on perceptual capacity, can be used to better understand clinical disorders.

There are also a number of disorders in which increased perceptual load is necessary to observe the effects of the load theory model. Remington, Swettenham, and Lavie (2012) hypothesized that the load theory model, with its focus on perceptual capacity, may be a means of resolving the discrepancies in previous studies in which individuals with autism spectrum disorder (ASD) displayed improved attentional abilities (e.g., improved performance in visual search tasks) and yet greater distractibility. Indeed, Remington et al. found that high perceptual load reduced distractor interference in normal adults but not in people with ASD. Further studies have shown that under extremely high perceptual load, there is no difference between ASD participants and controls (Hessels, Hooge, Snijders, \& Kemner, 2014). Children with autism have been found to be less susceptible to inattentional blindness than controls, and whereas increases in perceptual load are associated with increased inattentional blindness in controls, children with autism were unaffected by load increases (Swettenham et al., 2014). Interestingly, in a study of neurotypical individuals, those who scored above average on the Autism Spectrum Quotient suffered from greater distractor interference at high load than those who scored below average (Bayliss \& Kritikos, 2011). This suggests that even in nonclinical populations, autistic symptoms are associated with individual differences in selective attention under load. Deaf individuals also appear to provide a caveat for perceptual load theory, due to their apparently enhanced visual capacity limits. High perceptual load, sufficient to eliminate distractor interference in hearing participants, had no effect on deaf participants (Hauthal, Neumann, \& Schweinberger, 2012). In contrast, adults with attention deficit hyperactivity disorder (ADHD) experienced increased distraction as compared to controls, but increasing perceptual load was found to be equally effective at reducing distractor interference for both groups (Forster, Robertson, Jennings, Asherson, \& Lavie, 2014). Because perceptual load theory is rooted in the notion of a limited perceptual capacity, studies with groups known (or suspected) to have altered capacities are useful in examining the model and how it functions. The results of these studies support the most central tenet of load theory, that attention is constrained by perceptual capacity and, as predicted, deviations from average capacity can alter the predictions of the model. In turn, load theory, with its clear predictions and large body of evidence, may allow us better insight into how the process of attention is affected by such disorders.

In daily life, too, perceptual load can be affected by individual differences. Forster and Lavie (2007b) investigated the relationship between load and everyday distractibility. Distractibility was measured by the Cognitive Failures Questionnaire (CFQ; Broadbent, Cooper, FitzGerald, \& Parkes, 1982). The CFQ features questions such as "Do you find you forget why you went from one part of the house to the other?" and "Do you read something and find you haven't been thinking about it and must read it again?" They found that individuals who reported high levels of absent-mindedness in their everyday lives suffered from greater distraction by irrelevant stimuli under low load. However, under high load, distractor interference was reduced for all individuals, regardless of their general distractibility. The authors concluded that "high perceptual load makes everybody equal"- - that individual differences can be eliminated once a high enough level of load is reached. Interestingly, this relationship between everyday distractibility and distractibility in perceptual-load tasks has been discovered in relation to audio distractors also, with those scoring high on the CFQ displaying greater distractor interference effects in response to irrelevant auditory distractors (Murphy \& Dalton, 2014). A related study also uncovered evidence that perceptual load can eliminate the effect of internal sources of distraction (i.e., mind wandering; Forster \& Lavie, 2009).

Attentional control theory (Eysenck, Derakshan, Santos, \& Calvo, 2007) posits that trait anxiety reduces the influence of goal-directed attention and increases the extent to which attention allocation is stimulus-driven (Corbetta \& Shulman, 2002). Thus, in situations in which attentional resources are strained, highly anxious individuals are expected to exhibit greater distractor interference. This could be considered to be in opposition to the predictions of load theory, in which increased perceptual load is claimed to exhaust perceptual capacity and result in decreased distractor interference. Recent research has examined how attention is modulated by load in individuals high in trait anxiety. An fMRI study showed a negative correlation between trait anxiety and activity in the dorsolateral prefrontal cortex under low perceptual load, despite no significant effect on performance (Bishop, 2009). Highly anxious individuals appear to be able to compensate for this deficit by exerting more effort, and so at low load, there is no observable behavioral difference between those with high and low anxiety. This is in line with the predictions of attentional control theory (Eysenck et al., 2007). However, at high load, when attentional resources are exhausted, increased distractor interference is evident in highly anxious individuals (Sadeh \& Bredemeier, 2011). This is what is predicted by attentional control theory, but not by load theory. It appears that increased distractor processing in individuals high in anxiety is not overcome by typical load effects, as it is in those who are high in distractibility (Forster \& Lavie, 2007b) and individuals diagnosed with ADHD (Forster et al., 2014). The attentional dysregulation caused by trait anxiety appears to be resistant to the effects of high load, though it is difficult to definitively conclude that interference persists under high load in an anxious population. In the studies discussed, a task was designed that was presumed to impose high perceptual load; for the control population, this was apparently achieved and distractor interference was 
significantly reduced. It is possible that the task did not constitute high enough load for the anxious group - that they have increased perceptual capacity and that, with a more demanding task, load effects would be restored. This is a common methodological flaw in individual differences perceptualload research, and it makes concrete conclusions difficult.

These studies do illustrate that individuals high in trait anxiety perform differently under the same amount of perceptual load. Research on personality traits such as anxiety can benefit our understanding of attention under load, highlighting situations in which the load model is not upheld and prompting interesting questions as to why that would be the case. This line of research also provides valuable insight as to how attention is affected by the trait in question (e.g., perceptual load is a factor that can engender increased distraction in highly anxious individuals). What seems clear is that load theory is not a one-size-fits-all approach, and that individual differences in cognitive and emotional factors can moderate the effects of load. At present there is little evidence that other personality traits interact with perceptual load, but this is a question worthy of future investigation.

The effect of state anxiety on load effects has also been examined - though surprisingly few studies have been published on this topic, given the importance of stress in understanding load in applied contexts and some evidence suggesting that state and trait anxiety have different effects on attentional processes (Pacheco-Unguetti, Acosta, Callejas, \& Lupiáñez, 2010). Acute stress has been shown to influence the effects of perceptual load (Sato, Takenaka, \& Kawahara, 2012). Participants underwent the Trier Social Stress Test before completing a flanker task, with self-report and salivary cortisol measures confirming the increase in stress levels. Control (nonstressed) participants experienced distractor interference under low but not under high load, as is predicted by load theory. Interestingly, stressed participants displayed the opposite pattern of effects. Under low load, stressed participants experienced no distractor interference, suggesting that stress may recruit the same resources as attention. Under high load, however, stressed participants experienced significant distractor interference. Whereas the combination of low load and stress mimics the effects of high load and eliminates the interference effect, it may be that high load and stress amounts to excessive load. The authors surmised that such a burden disrupts top-down maintenance, affecting the dorsal fronto-parietal network (Corbetta, Patel, \& Shulman, 2008). The concept of excessive load requires validation in further studies, and we would also suggest that more work should be conducted assessing the effect of transient, everyday stress on perceptual load-for example, driver distraction in low- and high-load driving scenes, when completing a stressful timelimited task.

Because top-down control is so central to the predictions of load theory, it is logical that mental fatigue would also have an impact on performance. In a recent study, the effect of timeon-task at different levels of perceptual load was examined (Csatho, van der Linden, Hernadi, Buzas, \& Kalmar, 2012). Participants performed a flanker task for $2.5 \mathrm{~h}$ without breaks, at low, medium, and high perceptual load. Under low perceptual load, fatigue led to greater interference effects, indicative of difficulty maintaining top-down control of priorities. However, at medium and high load, fatigue had no such effect. The effects of both fatigue and acute stress are extremely relevant for the application of load theory to our understanding of realworld distraction, in particular because high-load everyday tasks (such as driving in difficult conditions) are likely to also induce fatigue and stress.

\section{Attentional plasticity in video-game players}

A fascinating strand of research in the area of individual differences under load is looking at attention in video-game players (see Hubert-Wallander, Green, \& Bavelier, 2011, for a review). Experienced video-game players have provided evidence for the plasticity of perceptual capacity limits. In particular, action video games seem to have an effect on performance under load, with individuals who regularly play these games seeming less affected by increases in load in a central task (Cohen, Green, \& Bavelier, 2007). These are firstor third-person games such as Halo, Medal of Honor, and Call of Duty, which require the player to monitor the simulated environment and respond quickly to the presence of targets among distractors (Achtman, Green, \& Bavelier, 2008). Critically, the attentional benefits of such games are evident across a number of tasks outside of gaming situations, including traditional load theory paradigms (Dye, Green, \& Bavelier, 2009). This suggests that something about regularly playing action video games actually increases an individual's perceptual capacity. For a model like load theory, which is founded on the principle of perceptual capacity, this line of research is of extreme interest. Studies have shown that both children and adult action-video-game players experience a much higher degree of interference from distractors under high perceptual load (Dye et al., 2009; Green \& Bavelier, 2003, 2006). As load increases, distractor interference is eliminated in nongamers but not in gamers, which may indicate that gamers have an increased perceptual capacity. Overall, gamers are also much faster at search tasks across all levels of load and congruency. Gamers are more accurate than nongamers under all conditions, and this effect holds even when they are performing a concurrent central task, ruling out the possibility that this effect derives from improved direction of attention (Green \& Bavelier, 2006). The benefits of gaming in other tasks such as the attentional blink paradigm (Green \& Bavelier, 2003) suggest that these studies reflect real improvements in visual attention rather than greater distractibility (Lavie, 2005). One problem with this area of research is that, to date, studies have 
simply designed conditions of low and high load and presented them to gamers and nongamers. Distractor interference effects are preserved in gamers under high load, and thus it could be concluded that they have a larger perceptual capacity-that is, what constitutes high perceptual load to a nongamer may be low or moderate load to an experienced gamer. It will be impossible to be certain of this conclusion, though, until a study is conducted that explores the threshold for high load in gamers. If these gaming effects are due to increased perceptual capacity, then load effects should be restored once the task imposes a sufficiently high level of load.

Importantly, studies have shown a causal relationship between gaming and improved perceptual capacity. In such studies, participants are required to play either fast-paced action games or control games. Those in the action-video-game group show significantly greater pre- to posttest improvements in many selective attention tasks (Cohen, Green, \& Bavelier, 2007; Feng, Spence, \& Pratt, 2007; Green \& Bavelier, 2003, 2006, 2007). Furthermore, two such studies have followed up on participants and tested them a third time, from several months to several years after the experiment (Feng et al., 2007; Li, Polat, Makous, \& Bavelier, 2009). with both studies showing that the majority of participants retained their training-related improvements over time.

In an fMRI study investigating attentional network recruitment, moving distractors were found to result in less activation of the brain area associated with motion sensitivity (middle temporal complex) in gamers than in nongamers (Bavelier, Achtman, Mani, \& Föcker, 2012). This is indicative of better early filtering of irrelevant stimuli in gamers. As perceptual load increased, nongamers showed greater recruitment of the fronto-parietal network areas known to be involved with the control of attention (see Fig. 5). This reduced neural activity in video-game players is in line with the hypothesis that the players develop more efficient attentional processes, and therefore respond to increasing perceptual load in a different manner than nongamers. These results provide further confirmation of the tenets of load theory, demonstrating that the locus of the attentional filter is dependent on the point at which perceptual capacity is exhausted.

This area of research will be important for the future of load theory, because it remains the most convincing evidence that load theory might scale up to dynamic, continuous, complex tasks outside the laboratory. It is also significant because it suggests that selective attention performance can be improved. Perhaps the type of training that video-game players undergo is also evident in other populations. The most obvious example here is experienced drivers, particularly professional drivers (i.e., ambulance drivers or police officers), who may become accustomed to high-speed, high-stakes target searches, just as action-video-game players do.

\section{Criticisms of and alternatives to load theory}

\section{Defining "load"}

Perhaps the most urgent criticism of perceptual-load research is the nebulous nature of the term "perceptual load" itself. Though emerging neural explanations are promising and useful, in behavioral terms, perceptual load is more clearly defined by paradigms (e.g., set size manipulations or target/ distractor similarity) than by explicit, process-based definitions (Benoni \& Tsal, 2013). What is high perceptual load? Load that is sufficient to prevent the processing of distractors. What does high perceptual load $d o$ ? It prevents the processing of distractors. There is a circularity here that makes unambiguous refutation rather difficult (Roper, Cosman, \& Vecera, 2013). If the expected results are not observed under "high load," then is this a true result, or simply a reflection of an unsuccessful load manipulation? One can imagine that this uncertainty might lead to many well-intentioned scientists interfering with experiments at the piloting stage, by continuing to manipulate load until the expected results appear. When

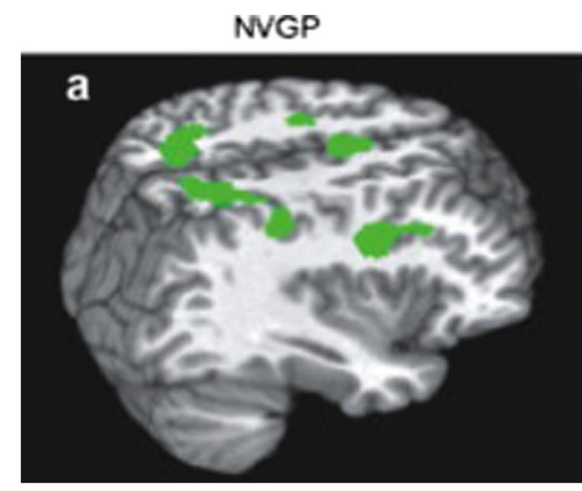

Fig. 5 Activation as perceptual load is increased for non-video-game players (NVGP, left) and experienced video-game players (VGP, right) (Bavelier et al., 2012). Video-game players demonstrated markedly less recruitment of the fronto-parietal network than did nongamers. From

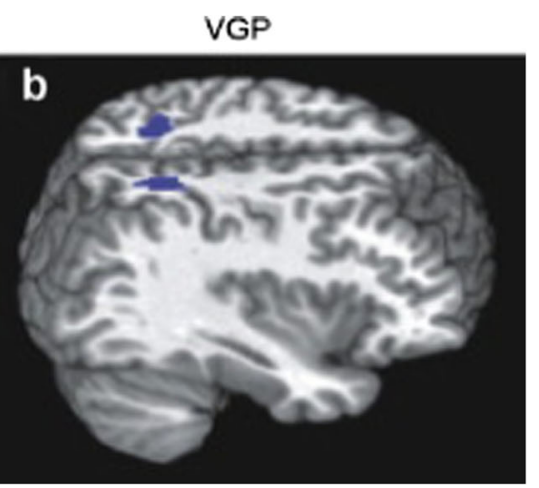

"Neural Bases of Selective Attention in Action Video Game Players," by Bavelier, Achtman, Mani, \& Föcker, 2012, Vision Research, 61, p. 138. Copyright 2011 by Elsevier Ltd. Reprinted with permission. 
variable $X$ is selected because of its observed relationship with variable $\mathrm{Y}$, it can no longer be considered truly independent (Kriegeskorte, Simmons, Bellgowan, \& Baker, 2009). This can lead to inflated effect sizes and "voodoo correlations" (Kingstone, Smilek, Ristic, Friesen, \& Eastwood, 2003). A recent attempt by Roper, Cosman, and Vecera (2013) to delineate the factors that influence perceptual load is an important next step for load theory. In order for the field to move forward, a clear operational definition of perceptual load needs to be established and agreed upon. Until then, cross-paradigm comparisons remain difficult.

Other researchers have criticized cognitive load and its role in the load model. As we discussed in the Cognitive Load section, there is some ambiguity as to what constitutes cognitive load, with different effects being observed in maintenance-based memory tasks versus tasks requiring cognitive control. Another issue faced by researchers in this field is disentangling perceptual and cognitive load. With both concepts lacking a clear operational definition, achieving a clean manipulation of either or both is incredibly difficult. This difficulty is only magnified when load theory is applied to more complex real-world tasks. For example, in Marciano \& Yeshurun's, 2012 and 2015 studies, perceptual load was manipulated in a driving context. Central perceptual load was manipulated via the number and congestion of vehicles on the road surrounding the participant's vehicle, whereas peripheral perceptual load was manipulated via the number of roadside objects such as pedestrians, buildings, and so forth. One could argue that as the number of vehicles on the road increases, not only is perceptual load affected, but cognitive load also. As drivers attend to more vehicles on the road, this increases the amount of information to be processed (perceptual load), but likely they also have to make more judgments about their own speed, the distance to the car in front, the intended actions of the drivers around them, and so on. Does this constitute a confound with cognitive load? With the current lack of clarity regarding cognitive load manipulations and their effects, it remains difficult to say. In the interests of applied future research, it is crucial that a more precise definition of cognitive load (and how exactly it differs from perceptual load in practice) should be agreed upon.

\section{Dilution}

Some researchers have offered alternative explanations for the patterns of results observed under load. Yehoshua Tsal, the coauthor of the study that first proposed the load hypothesis (Lavie \& Tsal, 1994). has been one of the most vocal critics of the theory. Tsal and colleagues have proposed an alternative explanation for much of the existing load theory evidence: dilution. Many experiments manipulate load by varying the number of items in the display (e.g., Lavie, 1995). Under low load, the potentially interfering distractor is presented alone, whereas under high load this distractor may be surrounded by other distractor letters. Tsal has argued that the distractor is processed to the same degree in both instances, but in the high-load condition, the interference caused by the distractor is diluted by the presence of the neutral stimuli (Tsal \& Benoni, 2010). Tsal and Benoni conducted a series of experiments that separated load and dilution effects (see Fig. 6). In one study, they compared displays that had low load, low dilution (Fig. 6A); high load, high dilution (Fig. 6B); and low load, high dilution (Fig. 6C). The two high-dilution displays contained the same numbers of items, but the low-load condition featured a target that was clearly distinguishable from the neutral items (due to a different-color font). Thus although perceptual load differed between the two conditions, the degree of dilution was controlled for. They found that distractor interference effects were evident in both the low-load, lowdilution condition and the high-load, high-dilution condition, but this was eliminated in the low-load, high-dilution display. Furthermore, when dilution was controlled for, Tsal and Benoni found that high perceptual load resulted in greater distractor interference than low load. The authors concluded from these studies that the display size effects predicted by load theory have been "misattributed to perceptual load [and are] fully accounted for by dilution" (p. 1645). This interpretation has received support from a number of studies (Benoni \& Tsal, 2012; Biggs \& Gibson, 2014; Chen \& Cave, 2013; Dittrich \& Stahl, 2011; Marciano \& Yeshurun, 2011).

However, Tsal and Benoni's (2010) conclusions were criticized in a response by Lavie and Torralbo (2010). who maintained that the dilution argument is built on a misunderstanding of the load hypothesis - namely, the involuntary nature of attention spillover. They argued that just because the pop-out search in the low-load, high-dilution condition renders the processing of the additional stimuli in the array unnecessary does not mean that they will not be processed. In other words, the additional letters are being processed, they are simply not affecting the chosen dependent measure-response times to the target letter. This hypothesis suggests that if the additional neutral items in the array were replaced with responsecompeting distractors, then distractor interference effects would again be evident. Lavie and Torralbo conducted such an experiment and found evidence in support of the capacity spillover hypothesis, suggesting that irrelevant items are processed under conditions of low perceptual load, even with high dilution, in line with the load theory model.

Lavie (1997) also drew attention to research that had manipulated load with no change in set size - in which the display was identical across conditions but the complexity of the task changed between high- and low-load conditions (i.e., search for any red shape in low load, search for a red square in high load). Benoni and Tsal (2013). however, have also argued that such tasks fail to control the load on working memory, and as such, perceptual and cognitive load become 

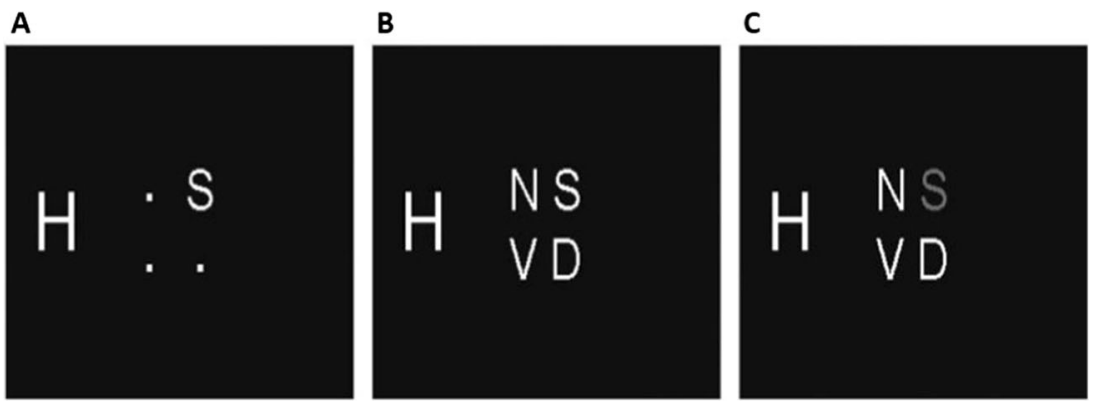

Fig. 6 Example stimuli from Benoni and Tsal (2010). Distractor interference was assessed under conditions of (A) low load, low dilution; (B) high load, high dilution; and (C) low load, high dilution. Participants indicated whether the target was an $\mathrm{H}$ or a $\mathrm{K}$, or a $\mathrm{C}$ or an $\mathrm{S}$, while ignoring the distractor letter (to the left), which could be congruent or incongruent with the target. The two high-dilution displays were

confounded (Fournier, Herbert, \& Farris, 2004). It should be noted that this problem does not apply to the discrimination task described earlier (Cartwright-Finch \& Lavie, 2006), in which participants view a briefly presented cross and are asked to make a low-load discrimination (which arm is blue?) or a high-load discrimination (which arm is longer?).

Recent publications have suggested that there may be a middle ground between dilution and load theory, and that the evidence for dilution indicates that the effect of neutral stimuli may be more complex than was previously assumed (Chen \& Cave, 2013; Scalf et al., 2013). A hybrid theory, which would fit well with theories of neural representation competition, may be the way to reconcile these opposing bodies of evidence. Scalf and colleagues (2013) proposed such a hybrid theory, rooted in the theory of biased competition discussed earlier. They suggest that the competition for neural representation among stimuli hinders their representation in the brain, and so both dilution and perceptual load have effects on attention. Dilution does occur and affects distractor processing; however, perceptual load, through top-down biasing signals, also determines the efficiency of selective attention.

\section{Other criticisms}

A number of other variables may need to be taken into account in revisions of classic load theory, such as the effects of distractor salience (Eltiti, Wallace, \& Fox, 2005; Koivisto \& Revonsuo, 2009) and spatial proximity (Paquet \& Craig, 1997). There is also evidence that high perceptual load only decreases processing of the distractor if there is a clear spatial separation between the target and the distractor. Research on object-based attention suggests that if the distractor is part of the target (e.g., in a Stroop task), then high perceptual load can actually increase distractor interference (Chen, 2003; Cosman \& Vecera, 2012). It is theorized that when the distractor and target are part of the same object, paying more attention to the target means paying more attention to the distractor. identical, except that the target letter was red in the low-load, highdilution condition, creating a pop-out effect. From "Where Have We Gone Wrong? Perceptual Load Does Not Affect Selective Attention," by Benoni \& Tsal, 2010, Vision Research, 50, p. 1293. Copyright 2010 by Elsevier Ltd. Adapted with permission.

Expectancy, as manipulated through precueing targets and running blocks of all high-load or all low-load trials, has also been shown to reduce or eliminate distractor interference in low-load conditions (Johnson, McGrath, \& McNeil, 2002; Sy, Guerin, Stegman, \& Giesbrecht, 2014; Theeuwes, Kramer, \& Belopolsky, 2004). Yet many other studies have presented blocks of either high- or low-load trials, in which load could be accurately predicted, and have still produced evidence in support of load theory (Beck \& Lavie, 2005; Forster \& Lavie, 2007b, 2008; Konstantinou \& Lavie, 2013)

Experiments that manipulate perceptual and cognitive load simultaneously (so called "sandwich tasks" like the one shown in Fig. 3) have shown that high perceptual load only reduces distractor interference when cognitive load is low (Linnell \& Caparos, 2011). One interpretation of this finding is that perceptual load induces early selection not because it exhausts perceptual capacity, but because it engages cognitive resources in a manner that focuses spatial attention (Linnell \& Caparos, 2013). The increased loads necessary for videogame players and individuals with autism (see the Individual Differences Under Load section above) may occur because lower loads are not sufficient to induce cognitive engagement. Linnell and colleagues proposed a default attentional state of engagement that can differ across cultures, citing evidence from the Himba, a remote population living in northern $\mathrm{Na}$ mibia, who appear to have more focused spatial attention that both British individuals living in London and Himba who now live in more urban areas (Linnell \& Caparos, 2013). Though the Himba displayed sensitivity to increases in perceptual load, they were capable of focused spatial attention at the very lowest level of load. Linnell and Caparos hypothesized that individuals living in fast-paced, dense urban environments favor late over early selection; that is, it is better to inefficiently take in all of the surrounding information, because distractors can so suddenly become targets. Remote communities like the Himba, however, have a default attentional state that fully engages cognitive resources with the task at hand. 
This, combined with evidence that increasing the social relevance of a display while keeping perceptual load constant induced early selection in the same manner as load (Linnell \& Caparos, 2013). suggests that further research will be needed to delineate perceptual load and attentional engagement. However, the effect of high cognitive load on distractor processing can perhaps be more simply explained in relation to the implementation of a top-down biasing signal to resolve stimulus competition. This signal draws on the same frontoparietal resources as traditional cognitive load tasks (e.g., working memory tasks; de Fockert et al., 2001; Lavie, 2005, 2010). Thus, when cognitive load is high, the resolution between target and distractor cannot easily be achieved, resulting in increased distractor interference effects relative to lowcognitive-load trials (Scalf et al., 2013).

Clearly, the evidence indicates that perceptual and cognitive load are not the only determinants of selective attention. Yet a wealth of evidence suggests that, under some circumstances at least, load is a major factor. Future research ought to examine other factors that contribute to selective attention under load and how they alter the load theory predictions. It is unlikely that load theory can explain attention in every instance, but instead attention may be determined by many factors. Remaining tied to any particular paradigm makes it difficult to ascertain how these factors work together to affect attention. Real-world research will be important for examining how load functions in complex, dynamic scenarios in which load is not the only contributing factor. Applied research is therefore a promising means of comparing the explanatory power of load theory to other approaches, such as dilution or attentional engagement.

\section{The future of load theory}

\section{Defining and operationalizing load}

As we have discussed throughout this article, a key criticism of load theory is the poor definition of "perceptual load" itself. In order for load theory to be advanced, a clear, operational definition of "load" must be agreed upon. Until a clear consensus on load is reached, it remains impossible to endorse or refute experimental results with certainty. Closely related to this is the question of how to operationalize load. Much of the evidence discussed in this review has arisen from variations on a single paradigm, a flanker search task involving letters. Experiments using faces and objects have also been conducted, but the vast majority of evidence for load theory is divorced from real-world applications of attention (Furley, Memmert, \& Schmid, 2013). Load theory does not stand alone in this regard; it has been suggested that many attentional research paradigms have failed to remain grounded in reallife behavior (Kingstone et al., 2003). Friesen and Kingstone
(1998) demonstrated the fallacy of deriving theories of attention from artificial paradigms. By replacing the arrows in the Posner cuing paradigm (Posner, 1978) with eye gazes, they found results that contrasted with the traditional findings of the paradigm. Remaining tied to one experimental paradigm can generate results that fail to generalize to real-life behavior, but of much more concern is that they can cloud and mislead understanding of the cognitive processes under investigation. As Meiser (2011, p. 185) excellently put it, the paradigm "turns from the tool of research to the target of research." The early- versus late-selection debate discussed at the beginning of this article is an apt example of this. Both camps employed different paradigms, and so quite understandably came to different conclusions about the nature of selective attention. What appeared to be contrasting evidence was in fact little more than a change in paradigm. As load theory emerged as a solution to this debate, researchers would do well not to go down the same path and become overly reliant on any one paradigm.

Reflecting on the issue of inflated effect sizes in neuroscience, Fiedler (2011) discussed the many methodological and theoretical issues that can arise from paradigmatic research. Among the many suggested solutions for this problem, and relevant to the furthering of load theory, is the introduction of a range of truly representative designs, amounting to convergent validations of effects (Garner, Hake, \& Eriksen, 1956). Instead of focusing on quantitative evaluation of the effect of perceptual load, we should perhaps look for qualitative confirmation of its existence across conditions with some relevance to real-world behavior. Kingstone and colleagues (2003, p. 176) remarked that "it is time for cognitive psychology to reaffirm the difficult task of studying attention in a manner that has relevance to real-life situations." Though they made this assertion in 2003, not much has changed in the decade since. Studying naturally occurring selective attention is indeed a challenge; however, as we have discussed, it is certainly a goal worth pursuing.

This issue of artificial research has become a somewhat tired criticism in cognitive psychology, one that could be levelled at almost any model. However, load theory appears to have the means to overcome this limitation, for a number of reasons. Perhaps most importantly, perceptual load manipulations are naturally occurring. The demand that is placed on attention when walking down a cluttered street filled with billboards, pedestrians, vehicles, cyclists, and all manner of sounds is very different from the demand placed by a quiet, rural street. The difference is clear and intuitively noticed. What we do not know intuitively is the effects that these different load environments have on our attention and awareness. Load theory can provide a framework to understand attention in these everyday contexts, because it makes clear, easily testable predictions about the interaction of perceptual and cognitive load. Though some work remains to be done to more 
clearly define the constructs involved, load theory has obvious applications in many domains.

Aside from having perhaps greater potential to overcome this issue, we also feel that load theory arguably has a greater responsibility to do so. Attention and distraction are key issues in many applied settings; for example, driver inattention has been found to be the main cause of road accidents in many naturalistic studies (e.g., Klauer, Dingus, Neale, Sudweeks, \& Ramsey, 2006). Predicting when and how and why we get distracted remains an important (if lofty) goal for applied cognitive psychology, with implications for dozens of applied settings. The ability to predict and, perhaps eventually, design environments that assist efficient attention in drivers, pilots, healthcare practitioners, and educators would represent one of the greatest contributions of cognitive psychology to society. Load theory has the potential to achieve this, as it makes strong predictions as to when additional information is processed and when distraction is more likely. Unlike some other cognitive theories, load theory seems almost designed to be applied in real-world settings, and can therefore be used to better understand and improve everyday attention.

The applications of load theory are numerous and exciting, and we will now discuss the existing applied studies and highlight some potential future directions.

\section{Real-world research}

Given that it is a theory that seeks to explain when distraction is likely to occur, load theory obviously has many real-world applications. Attention is crucial to many occupations (e.g., students, healthcare professionals) and activities (e.g., driving, sports), as well as to general daily functioning (e.g., reading this article from start to finish without repeatedly being distracted by the sights, sounds, and smells of the environment). The real-world applications of load theory have been alluded to in the literature; they are promising but often nebulous. However, in a study on perceptual load and distractibility, Forster and Lavie (2007b) found that under high perceptual load, individual differences in distractibility were eliminated. The authors recommended that this result should be applied to teaching: If a lecturer were to increase the perceptual load of a presentation (through hand gestures, content-heavy slides, etc.), this might benefit students who would otherwise be susceptible to distraction. This is a clear, verifiable application of load theory to real life, one of many that should be empirically tested. Given the current state of the model, it is somewhat difficult to estimate the effect of such an intervention - would increasing the content of the slides increase cognitive load as well as (or instead of) perceptual load? This is, however, an empirical question, and it can be directly assessed, provided that the expected effects of increased perceptual or cognitive load were explicitly described. These kinds of studies will be necessary to the progress of the theory in future, and they may result in many useful applications.

Preliminary steps have been taken in the transfer of load theory to the domain of sports (Furley et al., 2013). In an experiment examining expertise effects, Furley and colleagues assessed the performance of soccer players and nonsoccer players on a classic letter search task and a novel soccerspecific task (see Fig. 7). Participants were presented with a tactics board with two teams (Xs and Os) and had to determine which team had the ball, denoted by a small circle attached to the letter. The game constellations were meaningful, and load was manipulated by varying the number of "players" on the field. The goalkeeper served as an irrelevant distractor, as he never had the ball, and could be congruent (belonging to the same team as the player who had the ball) or incongruent. The predictions of load theory were upheld in this new, more meaningful paradigm; however, no effect of expertise was apparent in this context. This was perhaps due to the fact that tactics boards are not equivalent to playing soccer, so soccer players may not have sufficient experience with tactics boards to affect their attentional capacities. Though this experiment involved a search task for black-and-white letters, it represents a step toward confirming the applicability of load theory to real-life tasks. Future research examining expertise effects on high-load sports-related tasks could help to elucidate the nature of novice/expert differences in attention in sports, though the nature of the load task and its similarity to the sport would likely be crucial. Applying load theory to the vibrant area of sports psychology may ultimately allow enhanced sports performance. Load theory is rooted in perceptual capacity limits, and there is evidence from video-game players that perceptual capacity can be increased through targeted training. Could the same be achieved with high-level sports players? Using the load theory framework, perhaps better training could be designed to help athletes cope with high perceptual and cognitive load and/or the interaction of load with the stress, fatigue, and anxiety of competition. Furley and colleagues have begun to transfer load theory to the domain of sports, but there is still a long way to go before we can achieve an ecologically valid assessment of load in a sporting context. The potential benefits, however, are intriguing.

Other experimental studies have paved the way for further load theory applications. In a study investigating the effect of working memory load on distractor processing, Carmel, Fairnie, and Lavie (2012) presented participants with a highor low-load memory task (manipulated through set size) while the participants ignored irrelevant images. The results of a surprise quiz suggested that under high working memory load, participants were better at identifying faces that had been presented among the irrelevant images during the trial. This effect was only true for faces, not for irrelevant images of buildings. The authors pointed out the potential application of this result to our understanding of eyewitness testimony, a situation in 


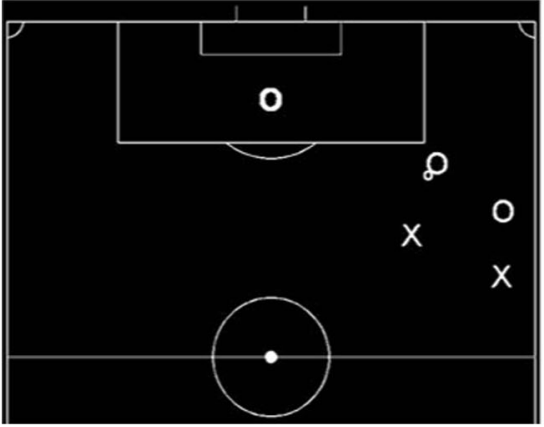

Fig. 7 Furley, Memmert, and Schmid (2013) translated a traditional load theory search task to a sports-related task. The task was to find which team (Xs or Os) was in possession of the ball (denoted by the small circle). Low-load trials (left) had fewer players than high-load trials (right), and the goalkeeper could be either congruent (left) or incongruent (right) with the team in possession. From "Perceptual Load

which irrelevant information suddenly becomes important. Future studies could elucidate the relationship between perceptual and cognitive load present in everyday life (e.g., using a mobile phone, having a conversation) and the ability to give reliable eyewitness reports. This research, along with many other of the studies discussed in this article, represents just the first step toward applying load theory to real-world issues. Because there is evidence that load impacts memory for seemingly irrelevant information, the next logical step would be to assess the effect of load using traditional eyewitness paradigms (e.g., viewing an event or a video of an event that imposes high or low perceptual load, and then answering questions, as in a real eyewitness situation). There is still some uncertainty as to how to apply these principles in a real-world forensic context. Even if we can illustrate that high perceptual load results in less accurate memories for everyday events, how would one establish that a crime had taken place under conditions of high perceptual load? Once again, we return to the idea of naturally occurring load and how exactly we can quantify it. Clearly, further research will be needed in this area, but there is great potential to make real-world contributions using load theory.

The research on load-induced inattentional blindness is also promising in terms of real-life applications. Along with the many mildly irritating incidents of inattentional blindness/ deafness that happen in everyday life, such as not seeing a friend waving at you from a crowd or not hearing someone calling your name when you're busy doing something else (Simons \& Chabris, 1999). it is thought that inattentional blindness may have a role to play in more serious performance failures. Drew, Võ, and Wolfe (2013) conducted a study in which 24 radiologists inspected a lung scan for nodules. An image of a gorilla, which was 48 times larger than the average nodule, was clearly visible on the scan, and yet $83 \%$ of the radiologists failed to detect it. Inattentional blindness may also be the cause of certain types of road accidents, such as when individuals report that another road user "just came out of

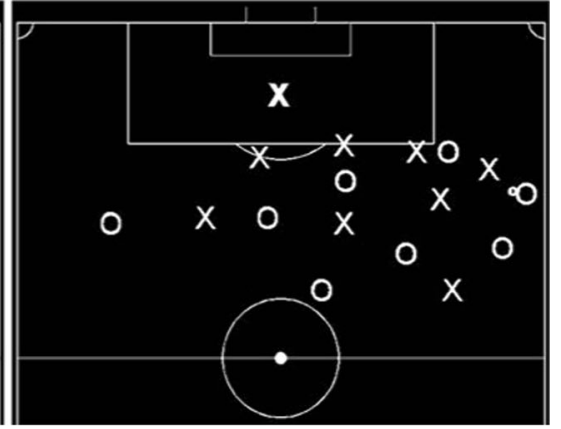

in Sport and the Heuristic Value of the Perceptual Load Paradigm in Examining Expertise-Related Perceptual-Cognitive Adaptations," by Furley, Memmert, \& Schmid, 2013, Cognitive Processing, 14, p. 35. Copyright 2012 by Marta Olivetti Belardinelli and Springer-Verlag. Adapted with permission.

nowhere." Common examples include drivers taking a right turn and cutting off an oncoming cyclist or motorcyclist (Simons, 2000). Understanding the role of load in such realworld instances of inattentional blindness is a clear avenue for future research. Experiments using a driving simulator, for example, would allow for assessments of inattentional blindness while participants engaged in a complex task in a dynamically changing environment. Furthermore, given that perceptual and cognitive load have been shown to affect levels of inattentional blindness, future inattentional blindness studies ought to control for the level of load imposed by the central task, to allow for more meaningful comparison between studies. Finding that inattentional blindness is greater for one stimulus than for another (e.g., for cyclists with and without a high-visibility neon jacket) is meaningless if the central tasks are imposing different levels of perceptual load (e.g., a rural road vs. a city-center intersection). Again, precise quantification of naturally occurring perceptual load will be key.

A number of studies have already applied load theory to driving (Marciano \& Yeshurun, 2012, 2015; Redenbo \& Lee, 2009). During a series of experiments in a driving simulator, Marciano and Yeshurun $(2012,2015)$ systematically manipulated perceptual load both on the road and on the sides of the road, while assessing measures of driving performance such as speed, response times to events, accident rates, and reactions to hazards presented centrally or peripherally. They found that, broadly in line with perceptual load theory, driving performance was moderated by the level of perceptual load in the environment. High load on the road mainly caused drivers to drive slower, whereas high load at the sides of the road negatively impacted their ability to detect safety-critical events originating from the roadside. These studies represent just a fraction of the potential applications of load theory to driving. As we discussed above, inattentional blindness may be responsible for many road accidents, and perceptual load is known to have a striking effect on levels of inattentional 
blindness (and deafness). Manipulating perceptual load in a naturally occurring manner (such as via roadside clutter) and examining the resultant levels of inattentional blindness for driving-relevant stimuli (such as pedestrians) would generate useful applied recommendations. Load theory could help to identify roads that may be beneficial or detrimental to driver attention via simple studies like this.

\section{Conclusion}

In this article, we have reviewed a broad range of studies on load theory. In recent years, researchers have moved beyond the early efforts to establish the effects of perceptual and cognitive load and begun adding "color" to the model, with research on cross-modal effects, individual differences, and more ecologically valid tasks advancing our understanding of how load influences distraction. We strongly feel that the crucial next step for load theory will be to investigate a wide range of real-world applications. Distraction is an issue in almost every occupation and activity, so the potential benefits of load theory applications are numerous. In order to progress to elegant experimental applications, first it will be necessary to form clearer definitions of perceptual and cognitive load. Process-based definitions, which clearly define perceptual load at a cognitive and/or neural level, would allow for more creative use of novel paradigms, which in turn would confirm the existence of load theory outside traditional paradigms. There are still unanswered questions with regard to individual differences under load, such as the potential interactions of perceptual and cognitive load with personality and intelligence. Question marks also remain over dilution, crossmodal attention, the effect of spatial separation between targets and distractors, and the role of object-based attention. Although valid criticisms remain, load theory is certainly a fruitful area of research. This is an exciting and fast-moving area, and we hope that this review will generate further interest and stimulate new ideas, as load theory makes its way out of the lab and into the world.

Author note This research was supported by an Irish Research Council, Government of Ireland, Postgraduate Scholarship to the first author, under the supervision of the last author.

\section{References}

Achtman, R. L., Green, C. S., \& Bavelier, D. (2008). Video games as a tool to train visual skills. Restorative Neurology and Neuroscience, 26, 435-446.

Allport, D. A., Antonis, B., \& Reynolds, P. (1972). On the division of attention: A disproof of the single channel hypothesis. Quarterly Journal of Experimental Psychology, 24, 225-235.
Baddeley, A. (1992). Working memory. Science, 255, 556-559. doi:10. 1126/science. 1736359

Baddeley, A. D. (2000). The episodic buffer: A new component of working memory? Trends in Cognitive Science, 4, 417-423. doi:10.1016/ S1364-6613(00)01538-2

Baddeley, A. D., \& Hitch, G. J. (1974). Working memory. In G. H. Bower (Ed.), The psychology of learning and motivation: Advances in research and theory (Vol. 8, pp. 47-89). New York: Academic. doi:10. 1016/S0079-7421(08)60452-1

Baddeley, A., \& Wilson, B. (1988). Frontal amnesia and the dysexecutive syndrome. Brain and Cognition, 7, 212-230. doi:10.1016/02782626(88)90031-0

Bavelier, D., Achtman, R. L., Mani, M., \& Föcker, J. (2012). Neural bases of selective attention in action video game players. Vision Research, 61, 132-143. doi:10.1016/j.visres.2011.08.007

Bayliss, A. P., \& Kritikos, A. (2011). Perceptual load and the autism spectrum in typically developed individuals. Journal of Autism and Developmental Disorders, 41, 1573-1578. doi:10.1007/ s10803-010-1159-8

Beck, D. M., \& Kastner, S. (2005). Stimulus context modulates competition in human extrastriate cortex. Nature Neuroscience, 8,1110 1116. doi:10.1038/nn1501

Beck, D. M., \& Lavie, N. (2005). Look here but ignore what you see: Effects of distractors at fixation. Journal of Experimental Psychology: Human Perception and Performance, 31, 592-607. doi:10.1037/0096-1523.31.3.592

Benoni, H., \& Tsal, Y. (2010). Where have we gone wrong? Perceptual load does not affect selective attention. Vision Research, 50, 1292 1298. doi:10.1016/j.visres.2010.04.018

Benoni, H., \& Tsal, Y. (2012). Controlling for dilution while manipulating load: Perceptual and sensory limitations are just two aspects of task difficulty. Psychonomic Bulletin \& Review, 19, 631-638. doi: 10.3758/s13423-012-0244-8

Benoni, H., \& Tsal, Y. (2013). Conceptual and methodological concerns in the theory of perceptual load. Frontiers in Psychology, 4, 522. doi: 10.3389/fpsyg.2013.00522

Berman, R. A., \& Colby, C. L. (2002). Auditory and visual attention modulate motion processing in area MT+. Cognitive Brain Research, 14, 64-74. doi:10.1016/S0926-6410(02)00061-7

Biggs, A. T., \& Gibson, B. S. (2014). Visual salience can co-exist with dilution during visual selection. Journal of Experimental Psychology: Human Perception and Performance, 40, 7-14. doi: 10.1037/a0033922

Bishop, S. J. (2009). Trait anxiety and impoverished prefrontal control of attention. Nature Neuroscience, 12, 92-98.

Bollinger, J., Masangkay, E., Zanto, T. P., \& Gazzaley, A. (2009). Age differences in $N 170$ amplitude modulation by selective attention and working memory load. Poster presented at the annual meeting of the Society for Neuroscience, Chicago, IL.

Brand-D'Abrescia, M., \& Lavie, N. (2008). Task coordination between and within sensory modalities: Effects on distraction. Perception \& Psychophysics, 70, 508-515. doi:10.3758/PP.70.3.508

Briggs, F., \& Usrey, W. M. (2011). Corticogeniculate feedback and visual processing in the primate. Journal of Physiology, 589, 33-40. doi: 10.1113/jphysiol.2010.193599

Broadbent, D. E. (1958). Perception and communication. London: Pergamon Press.

Broadbent, D. E., Cooper, P. F., FitzGerald, P., \& Parkes, K. R. (1982). The Cognitive Failures Questionnaire (CFQ) and its correlates. British Journal of Clinical Psychology, 21, 1-16.

Burnham, B. R. (2010). Cognitive load modulates attentional capture by color singletons during effortful visual search. Acta Psychologica, 135, 20-28.

Burnham, B. R., Sabia, M., \& Langan, C. (2014). Components of working memory and visual selective attention. Journal of Experimental 
Psychology: Human Perception and Performance, 40, 391-403. doi: $10.1037 / \mathrm{a} 0033753$

Calvillo, D. P., \& Jackson, R. E. (2014). Animacy, perceptual load, and inattentional blindness. Psychonomic Bulletin \& Review, 21, 670675. doi:10.3758/s13423-013-0543-8

Carmel, D., Fairnie, J., \& Lavie, N. (2012). Weight and see: Loading working memory improves incidental identification of irrelevant faces. Frontiers in Psychology, 3, 286. doi:10.3389/fpsyg.2012. 00286

Cartwright-Finch, U., \& Lavie, N. (2006). The role of perceptual load in inattentional blindness. Cognition, 102, 321-340.

Chen, Z. (2003). Attentional focus, processing load, and Stroop interference. Perception \& Psychophysics, 65, 888-900. doi:10.3758/ BF03194822

Chen, Z., \& Cave, K. R. (2013). Perceptual load vs. dilution: The roles of attentional focus, stimulus category, and target predictability. Frontiers in Cognition, 4(327), 1-14.

Cherry, E. C. (1953). Some experiments on the recognition of speech with one and with two ears. Journal of the Acoustical Society of America, $25,975-979$.

Cohen, J. E., Green, C. S., \& Bavelier, D. (2007). Training visual attention with video games: Not all games are created equal. In H. O'Neil $\&$ R. Perez (Eds.), Computer games and adult learning (pp. 205227). Amsterdam: Elsevier.

Connor, C. E., Preddie, D. C., Gallant, J. L., \& Van Essen, D. C. (1997). Spatial attention effects in macaque area V4. Journal of Neuroscience, 17, 3201-3214.

Corbetta, M., Patel, G. H., \& Shulman, G. L. (2008). The reorienting system of the human brain: From environment to theory of mind. Neuron, 58, 306-324. doi:10.1016/j.neuron.2008.04.017

Corbetta, M., \& Shulman, G. L. (2002). Control of goal-directed and stimulus-driven attention in the brain. Nature Reviews Neuroscience, 3, 201-215.

Cosman, J. D., \& Vecera, S. P. (2012). Object-based attention overrides perceptual load to modulate visual distraction. Journal of Experimental Psychology: Human Perception and Performance, 38, 576-579. doi:10.1037/a0027406

Couperus, J. W. (2011). Effects of perceptual load on selective attention across development. Developmental Psychology, 47, 1431-1439. doi:10.1037/a0024027

Csatho, A., van der Linden, D., Hernadi, I., Buzas, P., \& Kalmar, G. (2012). Journal of Cognitive Psychology, 24, 511-524. doi:10. 1080/20445911.2012.658039

Dalton, P., Lavie, N., \& Spence, C. (2009). The role of working memory in tactile selective attention. Quarterly Journal of Experimental Psychology, 62, 635-644.

de Fockert, J. W., Rees, G., Frith, C. D., \& Lavie, N. (2001). The role of working memory in visual selective attention. Science, 291, 18031806. doi:10.1126/science. 1056496

De Renzi, E. (2000). Prosopagnosia. In M. J. Farah \& T. E. Feinberg (Eds.), Patient-based approaches to cognitive neuroscience (pp. 85-96). Cambridge: MIT Press.

Desimone, R., \& Duncan, J. (1995). Neural mechanisms of selective visual attention. Annual Review of Neuroscience, 18, 193-222. doi:10.1146/annurev.ne.18.030195.001205

Deutsch, J. A., \& Deutsch, D. (1963). Attention: Some theoretical considerations. Psychological Review, 70, 80-90.

Dittrich, K., \& Stahl, C. (2011). Nonconcurrently presented auditory tones reduce distraction. Attention, Perception, \& Psychophysics, 73, 714-719. doi:10.3758/s13414-010-0064-8

Drew, T., Võ, M. L.-H., \& Wolfe, J. M. (2013). The invisible gorilla strikes again: Sustained inattentional blindness in expert observers. Psychological Science, 24, 1848-1853. doi:10.1177/ 0956797613479386
Driver, J. (2001). A selective review of selective attention research from the past century. British Journal of Psychology, 92, 53-78. doi:10. 1348/000712601162103

Ducato, M. G., Thomas, P., Monestes, J. L., Despretz, P., \& Boucart, M. (2008). Attentional capture in schizophrenia and schizotypy: Effect of attentional load. Cognitive Neuropsychiatry, 13, 89-111.

Duncan, J. (1980). The locus of interference in the perception of simultaneous stimuli. Psychological Review, 87, 272-300. doi:10.1037/ 0033-295X.87.3.272

Dye, M. W. G., Green, C. S., \& Bavelier, D. (2009). The development of attention skills in action video game players. Neuropsychologia, 47, 1780-1789. doi:10.1016/j.neuropsychologia.2009.02.002

Eltiti, S., Wallace, D., \& Fox, E. (2005). Selective target processing: Perceptual load or distractor salience. Perception \& Psychophysics, 67, 876-885. doi:10.3758/BF03193540

Engle, R. W. (2002). Working memory capacity as executive attention. Current Directions in Psychological Science, 11, 19-23. doi:10. 1111/1467-8721.00160

Eriksen, B. A., \& Eriksen, C. W. (1974). Effects of noise letters upon the identification of a target letter in a nonsearch task. Perception \& Psychophysics, 16, 143-149. doi:10.3758/BF03203267

Eysenck, M. W., Derakshan, N., Santos, R., \& Calvo, M. G. (2007). Anxiety and cognitive performance: Attentional control theory. Emotion, 7, 336-353. doi:10.1037/1528-3542.7.2.336

Farah, M. J., Wilson, K.-D., Drain, M., \& Tanaka, J. N. (1998). What is "special" about face perception? Psychological Review, 105, 482498. doi:10.1037/0033-295X.105.3.482

Feng, J., Spence, I., \& Pratt, J. (2007). Playing an action videogame reduces gender differences in spatial cognition. Psychological Science, 18, 850-855. doi:10.1111/j.1467-9280.2007.01990.x

Fiedler, K. (2011). Voodoo correlations are everywhere-Not only in neuroscience. Perspectives on Psychological Science, 6, 163-171. doi:10.1177/1745691611400237

Forster, S., \& Lavie, N. (2007a). Attentional capture by entirely irrelevant distractors. Visual Cognition, 16, 200-214.

Forster, S., \& Lavie, N. (2007b). High perceptual load makes everybody equal: Eliminating individual differences in distractibility with load. Psychological Science, 18, 377-382.

Forster, S., \& Lavie, N. (2008). Failures to ignore entirely irrelevant distractors: The role of load. Journal of Experimental Psychology: Applied, 14, 73-83. doi:10.1037/1076-898X.14.1.73

Forster, S., \& Lavie, N. (2009). Harnessing the wandering mind: The role of perceptual load. Cognition, 111, 345-355. doi:10.1016/j. cognition.2009.02.006

Forster, S., Robertson, D. J., Jennings, A., Asherson, P., \& Lavie, N. (2014). Plugging the attention deficit: Perceptual load counters increased distraction in ADHD. Neuropsychology, 28, 91-97. doi:10. 1037/neu0000020

Fougnie, D., \& Marois, R. (2007). Executive working memory load induces inattentional blindness. Psychonomic Bulletin \& Review, 14, 142-147. doi:10.3758/BF03194041

Fournier, L. R., Herbert, R. J., \& Farris, C. (2004). Demands on attention and the role of response priming in visual discrimination of feature conjunctions. Journal of Experimental Psychology: Human Perception and Performance, 30, 836-852. doi:10.1037/00961523.30.5.836

Friesen, C. K., \& Kingstone, A. (1998). The eyes have it! Reflexive orienting is triggered by nonpredictive gaze. Psychonomic Bulletin \& Review, 5, 490-495. doi:10.3758/BF03208827

Fu, S., Fedota, J., Greenwood, P. M., \& Parasuraman, R. (2010). Early interaction between perceptual load and involuntary attention: An event-related potential study. Neuroscience Letters, 468, 68-71.

Fu, S., Huang, Y., Fedota, J., Greenwood, P. M., \& Parasuraman, R. (2009). Perceptual load interacts with involuntary attention at early processing stages: Event-related potential studies. NeuroImage, 48, 191-199. 
Furley, P., Memmert, D., \& Schmid, S. (2013). Perceptual load in sport and the heuristic value of the perceptual load paradigm in examining expertise-related perceptual-cognitive adaptations. Cognitive Processing, 14, 31-42. doi:10.1007/s10339-012-0529-x

Garner, W. R., Hake, H. W., \& Eriksen, C. W. (1956). Operationism and the concept of perception. Psychological Review, 63, 149-159. doi: $10.1037 / \mathrm{h} 0042992$

Gauthier, I., Skudlarski, P., Gore, J. C., \& Anderson, A. W. (2000). Expertise for cars and birds recruits brain areas involved in face recognition. Nature Neuroscience, 3, 191-197.

Green, C. S., \& Bavelier, D. (2003). Action video games modify visual selective attention. Nature, 423, 534-537. doi:10.1038/nature01647

Green, C. S., \& Bavelier, D. (2006). Effects of action video game playing on the spatial distribution of visual selective attention. Journal of Experimental Psychology: Human Perception and Performance, 32, 1465-1478. doi:10.1037/0096-1523.32.6.1465

Green, C. S., \& Bavelier, D. (2007). Action-video-game experience alters the spatial resolution of vision. Psychological Science, 18, 88-94. doi:10.1111/j.1467-9280.2007.01853.x

Grill-Spector, K., Henson, R., \& Martin, A. (2006). Repetition and the brain: Neural models of stimulus-specific effects. Trends in Cognitive Sciences, 10, 14-23. doi:10.1016/j.tics.2005.11.006

Hains, P., \& Baillargeon, J. (2011). La face animale et le visage humain sont-ils équivalents? Une étude dans le cadre de la théorie de la charge perceptuelle. L'Année Psychologique, 111, 449-463. doi: 10.4074/S0003503311003010

Handy, T. C., Soltani, M., \& Mangun, G. R. (2001). Perceptual load and visuocortical processing: Event-related potentials reveal sensorylevel selection. Psychological Science, 12, 213-218. doi:10.1111/ 1467-9280.00338

Hauthal, N., Neumann, M. F., \& Schweinberger, S. R. (2012). Attentional spread in deaf and hearing participants: Face and object distractor processing under perceptual load. Attention, Perception, \& Psychophysics, 74, 1312-1320. doi:10.3758/s13414-012-0320-1

He, C., \& Chen, A. (2010). Interference from familiar natural distractors is not eliminated by high perceptual load. Psychological Research, 74, 268-276. doi:10.1007/s00426-009-0252-0

Henson, R., Shallice, T., \& Dolan, R. (2000). Neuroimaging evidence for dissociable forms of repetition priming. Science, 287, 1269-1272.

Hessels, R. S., Hooge, I. T. C., Snijders, T. M., \& Kemner, C. (2014). Is there a limit to the superiority of individuals with ASD in visual search? Journal of Autism and Developmental Disorders, 44, 443451.

Houghton, R. J., Macken, W. J., \& Jones, D. M. (2003). Attentional modulation of the visual motion aftereffect has a central cognitive locus: Evidence of interference by the postcategorical on the precategorical. Journal of Experimental Psychology: Human Perception and Performance, 29, 731-740. doi:10.1037/00961523.29.4.731

Huang-Pollock, C., Carr, T. H., \& Nigg, J. T. (2002). Development of selective attention: Perceptual load influences early versus late attentional selection in children and adults. Developmental Psychology, 38, 363-375.

Hubert-Wallander, B., Green, C. S., \& Bavelier, D. (2011). Stretching the limits of visual attention: The case of action video games. Wiley Interdisciplinary Reviews: Cognitive Science, 2, 222-230. doi:10. 1002/wcs.116

Ichida, J. M., Mavity-Hudson, J. A., \& Casagrande, V. A. (2014). Distinct patterns of corticogeniculate feedback to different layers of the lateral geniculate nucleus. Eye and Brain, 2014, 57-73. doi:10.2147/ EB.S64281

Jacoby, O., Hall, S. E., \& Mattingley, J. B. (2012). A crossmodal crossover: Opposite effects of visual and auditory perceptual load on steady-state evoked potentials to irrelevant visual stimuli. NeuroImage, 61, 1050-1058. doi:10.1016/j.neuroimage.2012.03. 040
Jenkins, R., Lavie, N., \& Driver, J. (2005). Recognition memory for distractor faces depends on attentional load at exposure. Psychonomic Bulletin \& Review, 12, 314-320. doi:10.3758/ BF03196378

Johnson, D. N., McGrath, A., \& McNeil, C. (2002). Cuing interacts with perceptual load in visual search. Psychological Science, 13, 284 287.

Jones, E. G. (1985). The thalamus. New York: Plenum.

Kahneman, D., \& Treisman, A. (1984). Changing views of attention and automaticity. In R. Parasuraman \& D. R. Davies (Eds.), Varieties of attention (pp. 29-61). New York: Academic.

Kanwisher, N., McDermott, J., \& Chun, M. M. (1997). The fusiform face area: A module in human extrastriate cortex specialized for face perception. Journal of Neuroscience, 17, 4302-4311.

Kastner, S., De Weerd, P., Desimone, R., \& Ungerleider, L. G. (1998). Mechanisms of directed attention in the human extrastriate cortex as revealed by functional MRI. Science, 282, 108-111. doi:10.1126/ science. 282.5386 .108

Kelley, T. A., \& Lavie, N. (2010). Working memory load modulates distractor competition in primary visual cortex. Cerebral Cortex, 21, 659-665. doi:10.1093/cercor/bhq139

Khetrapal, N. (2010). Load theory of selective attention and the role of perceptual load: Is it time for revision? European Journal of Cognitive Psychology, 22, 149-156. doi:10.1080/ 09541440902787014

Kingstone, A., Smilek, D., Ristic, J., Friesen, C. K., \& Eastwood, J. D. (2003). Attention, researchers! It is time to take a look at the real world. Current Directions in Psychological Science, 12, 176-180.

Klauer, S. G., Dingus, T. A., Neale, V. L., Sudweeks, J. D., \& Ramsey, D. J. (2006). The impact of driver inattention on near-crash/crash risk: An analysis using the 100-car naturalistic driving study data (Report No. DOT HS 810 594). Washington: National Highway Traffic Safety Administration.

Klemen, J., Büchel, C., \& Rose, M. (2009). Perceptual load interacts with stimulus processing across sensory modalities. European Journal of Neuroscience, 29, 2426-2434. doi:10.1111/j.1460-9568.2009. 06774.x

Koivisto, M., \& Revonsuo, A. (2009). The effects of perceptual load on semantic processing under inattention. Psychonomic Bulletin \& Review, 16, 864-868. doi:10.3758/PBR.16.5.864

Konstantinou, N., Beal, E., King, J., \& Lavie, N. (2014). Working memory load and distraction: Dissociable effects of visual maintenance and cognitive control. Attention, Perception, \& Psychophysics, 76, 1985-1997.

Konstantinou, N., \& Lavie, N. (2013). Dissociable roles of different types of working memory load in visual detection. Journal of Experimental Psychology: Human Perception and Performance, 39, 919-924. doi:10.1037/a0033037

Kriegeskorte, N., Simmons, W. K., Bellgowan, P. S. F., \& Baker, C. I. (2009). Circular analysis in systems neuroscience- the dangers of double dipping. Nature Neuroscience, 12, 535-540.

LaBerge, D. (1975). Acquisition of automatic processing in perceptual and associative learning. In P. M. A. Rabbit \& S. Dominic (Eds.), Attention and performance $V$ (pp. 50-64). New York: Academic.

Lavie, N. (1995). Perceptual load as a necessary condition for selective attention. Journal of Experimental Psychology: Human Perception and Performance, 21, 451-468. doi:10.1037/0096-1523.21.3.451

Lavie, N. (1997). Feature integration and selective attention: Response competition from unattended distractor features. Perception \& Psychophysics, 59, 543-556.

Lavie, N. (2005). Distracted and confused? Selective attention under load. Trends in Cognitive Sciences, 9, 75-82. doi:10.1016/j.tics. 2004.12.004

Lavie, N. (2010). Attention, distraction and cognitive control under load. Current Directions in Psychological Science, 19, 143-148. doi:10. 1177/0963721410370295 
Lavie, N., Beck, D. M., \& Konstantinou, N. (2014). Blinded by the load: Attention, awareness and the role of perceptual load. Philosophical Transactions of the Royal Society B, 370. doi:10.1098/rstb.2013. 0205

Lavie, N., \& Cox, S. (1997). On the efficiency of visual selective attention: Efficient visual search leads to inefficient distractor rejection. Psychological Science, 8, 395-398. doi:10.1111/j.1467-9280.1997. tb00432.x

Lavie, N., \& de Fockert, J. W. (2003). Contrasting effects of sensory limits and capacity limits in visual selective attention. Perception \& Psychophysics, 65, 202-212. doi:10.3758/BF03194795

Lavie, N., \& de Fockert, J. W. (2005). The role of working memory in attentional capture. Psychonomic Bulletin \& Review, 12, 669-674. doi:10.3758/BF03194795

Lavie, N., \& Fox, E. (2000). The role of perceptual load in negative priming. Journal of Experimental Psychology: Human Perception and Performance, 26, 1038-1052. doi:10.1037/0096-1523.26.3. 1038

Lavie, N., Hirst, A., de Fockert, J. W., \& Viding, E. (2004). Load theory of selective attention and cognitive control. Journal of Experimental Psychology: General, 133, 339-354. doi:10.1037/0096-3445.133.3. 339

Lavie, N., Ro, T., \& Russell, C. (2003). The role of perceptual load in processing distractor faces. Psychological Science, 14, 510-515.

Lavie, N., \& Robertson, I. (2001). The role of perceptual load in visual neglect: Rejection of ipsilesional distractors is facilitated with higher central load. Journal of Cognitive Neuroscience, 13, 867-876.

Lavie, N., \& Torralbo, A. (2010). Dilution: A theoretical burden or just load? A reply to Tsal and Benoni (2010). Journal of Experimental Psychology: Human Perception and Performance, 36, 1657-1664. doi:10.1037/a0020733

Lavie, N., \& Tsal, Y. (1994). Perceptual load as a major determinant of the locus of selection in visual attention. Perception \& Psychophysics, 56, 183-197. doi:10.3758/BF03213897

Li, R., Polat, U., Makous, W., \& Bavelier, D. (2009). Enhancing the contrast sensitivity function through action video game training. Nature Neuroscience, 12, 549-551. doi:10.1038/nn.2296

Lin, S.-Y., \& Yeh, S.-L. (2014). Attentional load and the consciousness of one's own name. Consciousness and Cognition, 26, 197-203.

Linnell, K. J., \& Caparos, S. (2011). Perceptual and cognitive load interact to control the spatial focus of attention. Journal of Experimental Psychology: Human Perception and Performance, 37, 1643-1648. doi:10.1037/a0024669

Linnell, K. J., \& Caparos, S. (2013). Perceptual load and early selection: An effect of attentional engagement? Frontiers in Psychology, 4, 498. doi:10.3389/fpsyg.2013.00498

Luck, S. J., Hillyard, S. A., Mouloua, M., Woldorff, M. G., Clark, V. P., \& Hawkins, H. L. (1994). Effects of spatial cuing on luminance detectability: Psychophysical and electrophysiological evidence for early selection. Journal of Experimental Psychology: Human Perception and Performance, 20, 887-904. doi:10.1037/00961523.20.4.887

Macdonald, J. S. P., \& Lavie, N. (2008). Load induced blindness. Journal of Experimental Psychology: Human Perception and Performance, 34, 1078-1091. doi:10.1037/0096-1523.34.5.1078

Macdonald, J. S. P., \& Lavie, N. (2011). Visual perceptual load induces inattentional deafness. Attention, Perception, \& Psychophysics, 73, 1780-1789. doi:10.3758/s13414-011-0144-4

Marciano, H., \& Yeshurun, Y. (2011). The effects of perceptual load in central and peripheral regions of the visual field. Visual Cognition, 19, 367-391. doi:10.1080/13506285.2010.537711

Marciano, H., \& Yeshurun, Y. (2012). Perceptual load in central and peripheral regions and its effects on driving performance: Advertising billboards. Work: A Journal of Prevention, Assessment and Rehabilitation, 41, 3181-3188.
Marciano, H., \& Yeshurun, Y. (2015). Perceptual load in different regions of the visual scene and its relevance for driving. Human Factors, 57, 701-716. doi:10.1177/0018720814556309

Maylor, E. A., \& Lavie, N. (1998). The influence of perceptual load on age differences in selective attention. Psychology and Aging, 13, 563-573. doi:10.1037/0882-7974.13.4.563

Meiser, T. (2011). Much pain, little gain? Paradigm-specific models and methods in experimental psychology. Perspectives on Psychological Science, 6, 183-191.

Miller, J. (1987). Priming is not necessary for selective-attention failures: Semantic effects of unattended, unprimed letters. Perception \& Psychophysics, 41, 419-434. doi:10.3758/BF03203035

Miller, E. K., Gochin, P. M., \& Gross, C. G. (1993). Suppression of visual responses of neurons in inferior temporal cortex of the awake macaque by addition of a second stimulus. Brain Research, 616, 25-29.

Moran, J., \& Desimone, R. (1985). Selective attention gates visual processing in the extrastriate cortex. Science, 229, 782-784. doi:10. 1126/science. 4023713

Moray, N. P. (1959). Attention in dichotic listening: Affective cues and the influence of instruction. Quarterly Journal of Experimental Psychology, 11, 56-60.

Moray, N. (1969). Attention: Selective processes in vision and hearing. London: Hutchinson Educational.

Mothes-Lasch, M., Miltner, W. H., \& Straube, T. (2012). Processing of angry voices is modulated by visual load. Neurolmage, 63, 485490. doi:10.1016/j.neuroimage.2012.07.005

Murphy, S., \& Dalton, P. (2014). Ear catching? Real-world distracibility scores predict susceptibility to auditory attentional capture. Psychonomic Bulletin \& Review, 21, 1209-1213. doi:10.3758/ s13423-014-0596-3

Neisser, U. (1969). Selective reading: A method for the study of visual attention. Paper presented at the 19th International Congress of Psychology, London, UK.

Neumann, M. F., Mohamed, T. N., \& Schweinberger, S. R. (2011). Face and object encoding under perceptual load: ERP evidence. NeuroImage, 54, 3021-3027. doi:10.1016/j.neuroimage.2010.10. 075

O’Connor, D. H., Fukui, M. M., Pinsk, M. A., \& Kastner, S. (2002). Attention modulates responses in the human lateral geniculate nucleus. Nature Neuroscience, 5, 1203-1209.

Pacheco-Unguetti, A. P., Acosta, A., Callejas, A., \& Lupiáñez, J. (2010). Attention and anxiety: Different attentional functioning under state and trait anxiety. Psychological Science, 21, 298-304. doi:10.1177/ 0956797609359624

Paquet, L., \& Craig, G. L. (1997). Evidence for selective target processing with a low perceptual load flankers task. Memory \& Cognition, 25, $182-189$.

Parks, N. A., Beck, D. M., \& Kramer, A. F. (2013). Enhancement and suppression in the visual field under perceptual load. Frontiers in Psychology, 4, 275. doi:10.3389/fpsyg.2013.00275

Parks, N. A., Hilimire, M. R., \& Corballis, P. M. (2009). Visual perceptual load modulates an auditory microreflex. Psychophysiology, 46, 498-501.

Parks, N. A., Hilimire, M. R., \& Corballis, P. M. (2011). Steady-state signatures of visual perceptual load, multimodal distractor filtering, and neural competition. Journal of Cognitive Neuroscience, 23, 1113-1124. doi:10.1162/jocn.2010.21460

Pinsk, M. A., Doniger, G. M., \& Kastner, S. (2004). Push-pull mechanism of selective attention in human extrastriate cortex. Journal of Neurophysiology, 92, 622-629.

Posner, M. I. (1978). Chronometric explorations of mind. Hillsdale: Erlbaum.

Posner, M. I. (1980). Orienting of attention. Quarterly Journal of Experimental Psychology, 32, 3-25. doi:10.1080/ 00335558008248231 
Rauss, K. S., Pourtois, G., Vuilleumier, P., \& Schwartz, S. (2009). Attentional load modifies early activity in human primary visual cortex. Human Brain Mapping, 30, 1723-1733. doi:10.1002/hbm. 20636

Redenbo, S. J., \& Lee, Y. C. (2009). Effects of cognitive and perceptual loads on driver behavior. Transportation Research Record, 2138, 20-27.

Rees, G., Frith, C. D., \& Lavie, N. (1997). Modulating irrelevant motion perception by varying attentional load in an unrelated task. Science, 278, 1616-1619. doi:10.1126/science. 278.5343 .1616

Rees, G., Frith, C., \& Lavie, N. (2001). Processing of irrelevant visual motion during performance of an auditory task. Neuropsychologia, 39, 937-949. doi:10.1016/S0028-3932(01)00016-1

Remington, A. M., Cartwright-Finch, U., \& Lavie, N. (2014). I can see clearly now: The effects of age and perceptual load on inattentional blindness. Frontiers in Human Neuroscience, 8, 229. doi:10.3389/ fnhum.2014.00229

Remington, A. M., Swettenham, J. G., \& Lavie, N. (2012). Lightening the load: Perceptual load impairs visual detection in typical adults but not in autism. Journal of Abnormal Psychology, 121, 544-551.

Reynolds, J. H., Chelazzi, L., \& Desimone, R. (1999). Competitive mechanisms subserve attention in macaque areas V2 and V4. Journal of Neuroscience, 19, 1736-1753.

Rissman, J., Gazzaley, A., \& D'Esposito, M. (2009). The effect of nonvisual working memory load on top-down modulation of visual processing. Neuropsychologia, 47, 1637-1646. doi:10.1016/j. neuropsychologia.2009.01.036

Ro, T., Friggel, A., \& Lavie, N. (2009). Musical expertise modulates the effects of visual perceptual load. Attention, Perception, \& Psychophysics, 71, 671-674. doi:10.3758/APP.71.4.671

Roper, Z., Cosman, J. D., \& Vecera, S. P. (2013). Perceptual load corresponds with factors known to influence visual search. Journal of Experimental Psychology: Human Perception and Performance, $5,1340-1351$

Roper, Z. J. J., \& Vecera, S. P. (2014). Visual short-term memory load strengthens selective attention. Psychonomic Bulletin \& Review, 21, 549-556. doi:10.3758/s13423-013-0503-3

Rorden, C., Guerrini, C., Swainson, R., Lazzeri, M., \& Baylis, G. C. (2008). Event related potentials reveal that increasing perceptual load leads to increased responses for target stimuli and decreased responses for irrelevant stimuli. Frontiers in Human Neuroscience, 2, 4. doi:10.3389/neuro.09.004.2008

Rose, M., Schmid, C., Winzen, A., Sommer, T., \& Büchel, C. (2005). The functional and temporal characteristics of top-down modulation in visual selection. Cerebral Cortex, 15, 1290-1298. doi:10.1093/ cercor/bhi012

Sabri, M., Humphries, C., Verber, M., Mangalathu, J., Desai, A., Binder J. R., \& Liebenthal, E. (2013). Perceptual demand modulates activation of human auditory cortex in response to task-irrelevant sounds. Journal of Cognitive Neuroscience, 25, 1553-1562. doi: 10.1162/jocn_a_00416

Sadeh, N., \& Bredemeier, K. (2011). Individual differences at high perceptual load: The relation between trait anxiety and selective attention. Cognition and Emotion, 25, 747-755.

Sato, S., \& Kawahara, J. (2014). Task-irrelevant faces capture attention regardless of perceptual load. Journal of Vision, 14(10), 319. doi:10. $1167 / 14.10 .319$

Sato, H., Takenaka, I., \& Kawahara, J. I. (2012). The effects of acute stress and perceptual load on distractor interference. Quarterly Journal of Experimental Psychology, 65, 617-623. doi:10.1080/ 17470218.2011 .648944

Scalf, P. E., Torralbo, A., Tapia, E., \& Beck, D. M. (2013). Competition explains limited attention and perceptual resources: Implications for perceptual load and dilution theories. Frontiers in Psychology, 4, 243. doi:10.3389/fpsyg.2013.00243
Schwartz, S., Vuilleunier, P., Hutton, C., Maravita, A., Dolan, R. J., \& Driver, J. (2005). Attentional load and sensory competition in human vision: Modulation of fMRI responses by load at fixation during task-irrelevant stimulation in the peripheral visual field. Cerebral Cortex, 15, 770-786. doi:10.1093/cercor/bhh178

Sherman, S. M., \& Guillery, R. W. (2001). Exploring the thalamus. San Diego: Academic.

Simons, D. J. (2000). Attentional capture and inattentional blindness. Trends in Cognitive Sciences, 4, 147-155. doi:10.1016/S13646613(00)01455-8

Simons, D. J., \& Chabris, C. F. (1999). Gorillas in our midst: Sustained inattentional blindness for dynamic events. Perception, 28, 10591074. doi:10.1068/p2952

Smith, E. E., Jonides, J., Koeppe, R. A., \& Marshuetz, C. (1998). Components of verbal working memory: Evidence from neuroimaging. Proceedings of the National Academy of Sciences, 95, 876882.

Sperling, G. (1960). The information available in brief visual presentations. Psychological Monographs: General and Applied, 74(11, Whole No. 498), 1-29.

Sreenivasan, K. K., \& Jha, A. P. (2007). Selective attention supports working memory maintenance by modulating perceptual processing of distractors. Journal of Cognitive Neuroscience, 19, 32-41. doi: 10.1162/jocn.2007.19.1.32

Swettenham, J., Remington, A., Murphy, P., Feuerstein, M., Grim, K., \& Lavie, N. (2014). Seeing the unseen: Autism involves reduced susceptibility to inattentional blindness. Neuropsychology, 28, 563570. doi:10.1037/neu0000042

Sy, J., \& Giesbrecht, B. (2010). fMRI evidence for top-down influences on perceptual distraction [Abstract]. Journal of Vision, 10(7), 212212a. doi:10.1167/10.7.212

Sy, J. L., Guerin, S. A., Stegman, A., \& Giesbrecht, B. (2014). Accurate expectancies diminish perceptual distraction during visual search. Frontiers in Human Neuroscience, 8, 344. doi:10.3389/fnhum. 2014.00334

Tellinghuisen, D. J., \& Nowak, E. J. (2003). The inability to ignore auditory distractors as a function of visual task perceptual load. Perception \& Psychophysics, 65, 817-828.

Theeuwes, J., Kramer, A. F., \& Belopolsky, A. V. (2004). Attentional set interacts with perceptual load in visual search. Psychonomic Bulletin \& Review, 11, 697-702. doi:10.3758/BF03196622

Thoma, V., \& Lavie, N. (2013). Perceptual load effects on processing distractor faces indicate face-specific capacity limits. Visual Cognition, 21, 1053-1076. doi:10.1080/13506285.2013.853717

Tipper, S. P. (1985). The negative priming effect: Inhibitory effects of ignored primes. Quarterly Journal of Experimental Psychology, $37 A, 571-590$

Torralbo, A., \& Beck, D. M. (2008). Perceptual load-induced selection as a result of local competitive interactions in visual cortex. Psychological Science, 19, 1045-1050.

Treisman, A. M. (1969). Strategies and models of selective attention. Psychological Review, 76, 282-299. doi:10.1037/h0027242

Treisman, A. M., \& Davies, A. (1973). Divided attention to ear and eye. In S. Kornblum (Ed.), Attention and performance IV (pp. 101-117). New York: Academic.

Tsal, Y., \& Benoni, H. (2010). Diluting the burden of load: Perceptual load effects are simply dilution effects. Journal of Experimental Psychology: Human Perception and Performance, 36, 1645-1656. doi:10.1037/a0018172

Vogel, E. K., \& Luck, S. J. (2000). The visual N1 component as an index of a discrimination process. Psychophysiology, 37, 190-203. doi:10. 1017/S0048577200981265

Wang, Y., Fu, S., Greenwood, P., Luo, Y. \& Parasuraman, R. (2012) Perceptual load, voluntary attention, and aging: An event-related potential study. International Journal of Psychophysiology, 84(1), 17-25. doi:10.1016/j.ijpsycho.2012.01.002 
Wei, P., Kang, G., \& Zhou, X. (2013). Attentional selection within and across hemispheres: Implications for the perceptual load theory. Experimental Brain Research, 225, 37-45. doi:10.1007/s00221012-3346-7

Wickens, C. D. (1980). The structure of attentional resources. In R. S. Nickerson (Ed.), Attention and performance VIII (pp. 239-257). Hillsdale: Erlbaum.

Wiggett, A. J., Pritchard, I. C., \& Downing, P. E. (2009). Animate and inanimate objects in human visual cortex: Evidence for taskindependent category effects. Neuropsychologia, 47, 3111-3117. doi:10.1016/j.neuropsychologia.2009.07.008

Wolfe, J. M. (1999). Inattentional amnesia. In V. Coltheart (Ed.), Fleeting memories: Cognition of brief visual stimuli (pp. 71-94). Cambridge: MIT Press.
Xu, J., Monterosso, J., Kober, H., Baldois, I. M., \& Potenza, M. N. (2011). Perceptual load-dependent neural correlates of distractor interference inhibition. PLoS ONE, 18, e14552. doi:10.1371/journal.pone.0014552

Yantis, S., \& Johnston, J. C. (1990). On the locus of visual selection: Evidence from focused attention tasks. Journal of Experimental Psychology: Human Perception and Performance, 16, 135-149. doi:10.1037/0096-1523.16.1.135

Yeshurun, Y., \& Marciano, H. (2013). Degraded stimulus visibility and the effects of perceptual load on distractor interference. Frontiers in Psychology, 4, 289. doi:10.3389/fpsyg.2013.00289

Yi, D.-J., Woodman, G. F., Widders, D., Marois, R., \& Chun, M. M. (2004). Neural fate of ignored stimuli: Dissociable effects of perceptual and working memory load. Nature Neuroscience, 7, 992-996. doi:10.1038/nn1294 